\title{
La movilidad social de los valencianos en Cataluña. Un estudio de caso a través de la Encuesta Sociodemográfica de 1991
}

\author{
Kenneth Pitarch \\ Rocío Treviño \\ Centre d'Estudis Demogràfics. Universitat Autònoma de Barcelona \\ kpitarch@ced.uab.cat; rtrevino@ced.uab.es
}

\section{Resumen}

En el presente trabajo se analiza el nivel de movilidad social intrageneracional e intergeneracional de uno de los grupos migrantes más antiguos de Cataluña, el valenciano, comparándolo con el resto de los grupos migrantes del resto de España. Dicho colectivo, a pesar de compartir algunos rasgos socioculturales e históricos con la población de Cataluña y de ser el más importante en dicho territorio hasta la década de 1930, no ha sido objeto de atención por parte de los académicos. La fuente principal utilizada ha sido la Encuesta Sociodemográfica de 1991. Para el análisis de la movilidad intrageneracional, se analizan las trayectorias laborales y económicas antes y después de migrar y, para el análisis de la movilidad intergeneracional, se utilizan tablas de entrada y de salida, así como una regresión multinomial y binomial. Los resultados apuntan a un mayor ascenso social de los valencianos en comparación con el resto de grupos migrantes, aunque algunos, como los castellanoleoneses o los aragoneses, se sitúan en niveles parecidos en algunas dimensiones de la movilidad.

Palabras clave: demografía; migración valenciana; Cataluña; herencia de clase; movilidad ocupacional; ascenso social; migración interna 
Abstract. The social mobility of Valencians in Catalonia: A case study based on the 1991 Sociodemographic Survey

In this paper, we analyse the level of intra- and intergenerational social mobility of one of the oldest migrant groups in Catalonia, the Valencians, and compare them to other migrant groups from the rest of Spain. Despite sharing some socio-cultural and historical features with the population of Catalonia and becoming the largest immigrant group until the 1930s, migrants from Valencia have not been the subject of attention for scholars. Using data from the Sociodemographic Survey of 1991, the labour and economic trajectories of this group are analysed before and after migration. For the analysis of intergenerational mobility, outflow and inflow tables as well as multinomial and binomial regression are used. The results point to a greater social ascent of the Valencians in comparison to other migrant groups, although some, such as those from Aragon or Castile-León show similar levels in some dimensions of mobility.

Keywords: demography; Valencian migration; Catalonia; class inheritance; occupational mobility; social ascent; internal migration

\section{Sumario}
Introducción
4. Los valencianos en 1991 en
1. Objeto de estudio e hipótesis Cataluña. Principales características sociodemográficas
2. Las oleadas migratorias y los estudios de movilidad social
3. Fuentes y metodología
5. Análisis y resultados
6. Conclusiones
Referencias bibliográficas

\section{Introducción}

Cataluña no habría alcanzado los 7,5 millones de personas que componen su población actual sin el efecto de la inmigración (Domingo, 2014). La continua llegada de personas procedentes de otras regiones de España producida desde finales del siglo XIX (Arango, 1976; Vidal y Recaño, 1996) y, en años más recientes, desde el extranjero (Domingo et al., 2012) contribuyó a disminuir el estancamiento demográfico que se hubiese producido por la baja fecundidad (Cabré, 1991-1992)․․ Si, a finales del siglo XX, el 60\% de la población catalana era fruto directo o indirecto de la inmigración (Cabré, 1999), tras el boom migratorio de la primera década del siglo XXI, es posible que este número haya aumentado al 70\%, e incluso más (Domingo, 2012).

El fuerte componente migratorio de la sociedad catalana sería utilizado por Vandellòs, uno de los primeros demógrafos del país, para apoyar las corrien-

1. Cabré (1991-1992) estimó que en ausencia de migraciones la población catalana no sobrepasaría los 2.371.785 habitantes en 1986, es decir, tendría un 60\% menos de población en ese momento. Es más, los catalanes descendientes exclusivamente de personas que habitaban Cataluña en 1900 — sin que eso significase tampoco que hubiesen nacido en dicha comunidad autónoma- serían tan solo un $25 \%$ a finales del siglo XX. 
tes eugenésicas de principios del siglo $\mathrm{XX}^{2}$. Posteriormente, desde el discurso social y desde la propia demografía, se señalaría que el componente secular y sostenido de la inmigración constituiría un elemento endógeno particular del sistema de reproducción demográfico en Cataluña (Cabré, 1999), destacando la superioridad de la reproducción social por encima de la biológica (Candel, 1964; Domingo, 2012). La reproducción social se apoyaría en los procesos de movilidad que experimentarían los inmigrantes de las diferentes oleadas migratorias llegadas en el siglo XX, que, siguiendo el curso del ciclo económico, habrían contribuido a crear un sistema de beneficio mutuo en la promoción social de autóctonos e inmigrantes, de modo que la inmigración se habría consolidado como un elemento indispensable, no solo de la reproducción demográfica, sino también social.

No obstante, el análisis de la movilidad social —entendida como un movimiento ascendente o descendente en el sistema de estratificación social— ha promovido escasos trabajos empíricos, quizás por una combinación de factores que van desde la dificultad que entronca su propio análisis — sobre todo debido a la escasez de fuentes estadísticas - hasta el empeño de incorporar la movilidad social ascendente de inmigrantes como emblema de la reproducción social catalana. Aparte del trabajo pionero de Pinilla de las Heras (1973), el estudio de esta materia a nivel autonómico ha sido más bien escaso, aunque a nivel estatal, tras la publicación de los primeros informes FOESSA en los años setenta y los trabajos de Carabaña en las siguientes dos décadas, la investigación en este campo aumentó considerablemente, especialmente a partir de los años noventa.

Sin embargo, los análisis de movilidad social pocas veces han distinguido los sujetos de estudio en función de su lugar de nacimiento. Quizás en países o regiones que reciban escasos flujos migratorios esto no sea relevante, pero en Cataluña, caracterizada por disponer de un sistema de reproducción demográfica y social en el que la aportación continua de población inmigrante se ha resaltado como un elemento tan esencial que ha llevado a denominarlo sistema català de reproducció (Cabré, 1999), la aportación de elementos empíricos que permitan situar a los diferentes grupos de inmigrantes en los procesos de movilidad social resulta una tarea ineludible y previa para entender los procesos de reproducción social. Para avanzar en el conocimiento de estos mecanismos y contribuir, así, a paliar dicho vacío, se analizará el nivel de movilidad social experimentado por una de las procedencias históricas con más antigüedad de la migración hacia Cataluña, la valenciana. El análisis se realizará a partir de la Encuesta Sociodemográfica de 1991, una fuente estadística excepcional, no solo por su amplia base muestral, sino también porque recoge información biográfica familiar, laboral y educativa de los sujetos encuestados.

2. Josep A. Vandellós i Solà era consciente de que el vacío demográfico provocado por la baja fecundidad en Cataluña se estaba supliendo con la llegada de inmigrantes, una «invasión pacífica» —en palabras del autor (1985: 58) — que provocaría irremediablemente la desnaturalización de Cataluña. Vandellós, incluso, exponía su preocupación por la desaparición de las "cualidades raciales catalanas» ante el avance de una corriente migratoria (andaluza y murciana especialmente) tan poderosa (1985: 56). 
El trabajo se estructura en seis partes. En la primera, se explican las motivaciones para elegir al grupo migrante valenciano como objeto de estudio y las hipótesis planteadas en este trabajo. En la segunda, se hace una pequeña descripción de las tres oleadas migratorias que sacudieron España durante el siglo XX junto a un breve recorrido bibliográfico de las investigaciones de movilidad social realizadas, tanto de las que se hicieron con datos de la Encuesta Sociodemográfica como de las que, en general, tenían como objeto de estudio a los inmigrantes protagonistas de las migraciones interprovinciales del período. En la tercera, se exponen las fuentes y la metodología utilizada. Seguidamente, en la cuarta, se analizan las principales características sociodemográficas de la población valenciana residente en Cataluña en 1991. A continuación, en quinto lugar, se exponen los resultados del análisis de la movilidad social de los valencianos en comparación con la de otros grupos migrantes del Estado. Finalmente, en la sexta parte, se presentan y se discuten los resultados.

\section{Objeto de estudio e hipótesis}

El estudio se focaliza en el colectivo inmigrante valenciano por los siguientes dos motivos. Primero, porque se trata del principal contingente de población inmigrante en Cataluña hasta mediados del siglo XX. Si bien actualmente representan una población de 62.000 personas $^{3}$, una cifra hasta diez veces inferior de la que constituyen los andaluces, en 1930 llegaban a 126.165, el 25\% de la población inmigrante proveniente del resto del Estado, por encima de los aragoneses — con 118.346 personas - y los murcianos — con 81.698 - (Pujadas, 1982) $)^{4}$. Y, segundo, porque, a diferencia de otros grupos inmigrantes de otras comunidades autónomas sobre los que más se ha trabajado en Cataluña — principalmente andaluces y gallegos (Pascual de Sans, 2011) —, los estudios sobre inmigración valenciana son casi inexistentes a pesar de la cercanía cultural, propiciada por, entre otras cosas, el uso del catalán —en su variante occidental - de muchos de los inmigrantes, la proximidad de ambos territorios y el recuerdo de una historia compartida.

Se plantean tres hipótesis de trabajo. La primera es que los inmigrantes valencianos llegados desde finales del siglo XIX hasta la década de 1970 mejoraron su situación respecto a la de sus progenitores y respecto a su situación antes de su llegada a Cataluña. La segunda es que la población inmigrada del País Valenciano experimentó, por lo general, una movilidad superior a la de otros orígenes o procedencias de España. Y la tercera hipótesis solo puede ser

3. En concreto, 62.215 personas según los últimos datos provisionales del padrón de 2018 .

4. Posteriormente, por el aumento de los flujos de llegada de otras zonas de España, la importancia relativa de la población valenciana descendió considerablemente. Desgraciadamente no sabemos con exactitud el año exacto en el que se produce el "cambio de liderazgo» en los grupos migrantes de Cataluña, ya que los censos llevados a cabo entre 1930 y 1970 solo especificaban si la persona registrada había nacido en la provincia de registro o en otra. Pese a eso, este se debía producir en la posguerra, con el inicio de la segunda oleada migratoria que llegaría a Cataluña. 
planteada, pero no contrastada, y está íntimamente relacionada con el porqué de la invisibilidad de la migración valenciana en Cataluña en comparación con la de otros orígenes, traducida en los escasos trabajos que abordan su estudio (González, 2007; Campmany, 2015; Domingo y Pitarch, 2015) ${ }^{5}$. Dicha invisibilidad, según nuestra última hipótesis, estaría atribuida, por un lado, a su antigüedad y, por otro lado, a una asimilación más rápida debido a la percepción de proximidad cultural. Los datos transversales y biográficos de la encuesta solo nos permiten verificar las dos primeras hipótesis, si bien con algunas limitaciones derivadas de la reducida muestra de valencianos residentes en Cataluña disponible en la Encuesta Sociodemográfica, a pesar de la magnitud de la misma para el conjunto del Estado y de ser única en su especie. Nos posibilitan, no obstante, aportar nuevas evidencias empíricas de la movilidad social de los inmigrantes en Cataluña y, en particular, de los valencianos con datos cuantitativos, dejando que futuros trabajos aborden el estudio detallado de sus determinantes acudiendo a fuentes cualitativas o documentales.

\section{Las oleadas migratorias y los estudios de movilidad social}

Desde los pioneros trabajos de García Barbancho (1967) o Capel (1967) —e incluso de Vandellós (1935), si nos referimos únicamente a Cataluñahasta los recientes de Silvestre $(2007,2010)$, numerosos académicos han establecido, con ligeras diferencias en torno a la periodización, tres grandes oleadas migratorias en España, caracterizadas las dos primeras por un protagonismo de las migraciones interiores y la tercera por el auge de las entradas procedentes del exterior.

El primer periodo se extendió desde mediados o finales del siglo XIX ${ }^{6}$ hasta el estallido de la Guerra Civil. Sin bien el conflicto bélico supuso el final de esta primera etapa, a principios de los años treinta los movimientos ya se habían empezado a mitigar. Respecto a Cataluña, en esta primera etapa atrajo sobre todo a inmigrantes de las áreas más cercanas, primeramente del País Valenciano y Aragón y más tarde de Murcia y Almería (Arango, 1976). Silvestre et al. (2015) distinguen, en esta primera oleada migratoria, el perfil de la migración de las primeras cohortes de llegada respecto a las últimas. En el primer caso, un perfil más elevado de los migrantes, una estructura ocupacional en destino menos diversificada y un menor peso de las ocupaciones no cualificadas carac-

5. Los pocos trabajos que hablan de la migración valenciana en Cataluña la han tratado como uno más de los orígenes de la migración interna española (Arango, 1976; Mirri, 1996; Oyón et al., 2001; Silvestre et al., 2015). Una excepción es el reciente trabajo de Domingo y Pitarch (2015), que realizan un análisis sociodemográfico actualizado de la población valenciana en Cataluña a partir de diversas fuentes del INE; el de González (2007), centrado en Actuació Valencianista d'Esquerra, un grupo político de izquierdas y republicano formado por inmigrantes valencianos en la ciudad de Barcelona en la década de 1930, y el de Campmany (2015), sobre la colonia valenciana de Gavà.

6. Algunos autores incluso señalan como fecha de inicio de la emigración permanente del campo a la ciudad en el siglo XIX la década de 1860 (Silvestre, 2010; Recaño, 1996). 
terizaron la situación del momento. Pero, a partir de la segunda década, la demanda de trabajo en grandes infraestructuras como la construcción del metro en Barcelona y la Exposición Universal de 1929 (Vilá, 1959; Olives, 1969; Pascual de Sans et al., 2002) atrajo a una migración con un perfil de cualificación más bajo que llegó en un momento de mayor diversificación de la estructura ocupacional en destino y con mayor cabida del trabajo no cualificado.

La segunda oleada se inició en los años cuarenta o cincuenta y se extendió hasta mediados de los años setenta, momento del estallido de la crisis del petróleo y la llegada de la democracia a España (García y Pujadas, 1995). El mantenimiento de un éxodo rural ya iniciado en décadas anteriores culminó un proceso de redistribución de población rural hacia las zonas de desarrollo industrial en esta nueva oleada (Silvestre, 2002). Esta vez, en Cataluña, los flujos procedentes del sur peninsular — principalmente de Extremadura y Andalucía- destacaron sobremanera frente a los del resto del país ${ }^{7}$. Es cierto que Cataluña y Madrid continuaron siendo los principales polos de atracción en España, pero en este periodo surgieron o se consolidaron otros dos puntos de recepción: la Comunidad Valenciana y el País Vasco ${ }^{8}$.

Finalmente, la tercera oleada, protagonizada por población extranjera, se inició a partir de los años ochenta y acabó en torno a la crisis económica del 2007. Durante este periodo, algunos territorios de destino que en décadas pretéritas habían sido grandes emisores de población —el Valle del Ebro, el litoral mediterráneo o los alrededores de la ciudad de Madrid - se convirtieron en centros de atracción (García y Stillwell, 1999). Pero lo más destacable de esta oleada fue lo que se conoció como el boom migratorio. Y es que, entre los años 2000 y 2010, llegaron a España algo más de cinco millones de inmigrantes, lo que provocó unas consecuencias demográficas jamás vistas antes (Cachón, 2002; Sabater et al., 2013; Galeano y Bayona, 2015).

Durante estas tres etapas, y a pesar de que desde la segunda oleada los flujos dirigidos al Principado fuesen sobrepasados ampliamente por los de otros orígenes, como Andalucía o Extremadura, la emigración valenciana ha tenido como destino principal Cataluña. En la primera y segunda etapas, además, adquirió carácter internacional ${ }^{9}$, aunque, debido al despegue de la economía valenciana a partir de los años sesenta, esos flujos se redujeron en

7. Durante esta segunda etapa, con máximos localizados a mediados de los años sesenta, Cataluña pasará de tener 3,2 millones de habitantes en 1951 a 5,6 en 1975 (Domingo, 2014).

8. En la Comunidad Valenciana el desarrollo de su economía disminuyó la intensidad de algunos flujos al exterior, aspecto que afectaría a las migraciones dirigidas a Cataluña. Sin embargo, no se puede afirmar que dejasen de llegar valencianos al Principado. De hecho, como se verá más adelante, el grueso de los valencianos que en 1991 vivía en el Principado llegó en las décadas de 1950 y 1960. Respecto al País Vasco, y más concretamente la provincia de Vizcaya, esta ya empezó a sobresalir como punto de atracción migratoria a finales del siglo XIX (Arbaiza, 1998), aunque la intensidad de sus flujos de atracción se encontraba muy por debajo de la de Cataluña y Madrid hasta esta segunda etapa.

9. Alcanzando determinados países donde su presencia se hizo notar, como Argelia (Bonmatí, 1989), los Estados Unidos (Morell, 2012), Francia (Babiano, 2001) o Latinoamérica (Pinotti y Cruz, 1992), por ejemplo. 
todas las direcciones, lo que convirtió al País Valenciano en un destino preferente, tanto para turistas (González, 2008) como para trabajadores del resto del Estado (Hermosilla, 1995) ${ }^{10}$. La investigación sobre la primera oleada migratoria ha estado muy desatendida en comparación con la segunda, en parte por las dificultades de su estudio debido a la escasez de fuentes, pero también por el menor desarrollo de las disciplinas sociales en el momento en que se produjo.

En cuanto a la temática de la movilidad social, esta ha sido abordada en España tardíamente en relación con la bibliografía anglosajona. La pionera obra Social Mobility, de Sorokin se publicó en 1927, fecha desde la cual los trabajos sobre esta materia experimentaron un crecimiento espectacular, especialmente tras la Segunda Guerra Mundial, tanto en Estados Unidos como en el resto de Europa (Echevarría, 1999). Sin embargo, en España, el interés que suscita esta disciplina no se generalizó hasta principios de la década de 1990 (Rodríguez, 1993), aunque en décadas anteriores aparecieron algunas investigaciones (Aranda, 1976; Pinilla de las Heras, 1979). Diferentes estudios (Roiz, 1983; Murillo et al., 1983) coinciden en señalar a Díez y del Pino (1972) como los autores de la mejor síntesis sobre los trabajos de movilidad social en España hasta la década de 1970. En estos años aparecieron también los primeros Informes FOESSA (1970, 1975), en los que se abordaba la movilidad, la estructura y la desigualdad social en España. Pero es en 1975 cuando Díez et al. marcaron un punto y aparte con un estudio bastante completo en el que, a través de variables como la ocupación y la educación, utilizaron modernos modelos de análisis y de indicadores. En él determinaron que la educación del padre jugaba un rol mucho más importante que la ocupación de cara a un posible ascenso social del hijo, aunque con matices. Además, uno de los aspectos importantes que señalaron al final del estudio, y que entronca con nuestro trabajo, era la necesidad de introducir en futuras investigaciones un análisis que tuviese en cuenta variables de origen regional.

Ahora bien, el auténtico despegue de los trabajos sobre movilidad social en España se consolidó en los años noventa con las obras de Lorenzo Cachón (1989) y Julio Carabaña. Carabaña $(1983,1990,1993)$. El manual que publicó Cachón en 1989 continúa siendo una obra de referencia para el estudio de la movilidad social en España, al recurrir a determinados estudios clásicos para discutir o corroborar ciertas metodologías de análisis desde diversas perspectivas. Carabaña, en uno de sus primeros estudios, concluyó que algunos de los rasgos de la sociedad estamental española todavía seguían estando muy presentes en la reproducción social en el último cuarto del siglo XX, como el rol de las alianzas matrimoniales, además de insistir en que se había de prestar más

10. A partir del año 2007, con el estallido de la crisis económica, los movimientos dirigidos al extranjero protagonizados por nacionales españoles desde el País Valenciano han vuelto a adquirir relevancia, al igual que pasó en otras partes de España. Esta vez, sin embargo, los destinos mayoritarios de esta nueva migración se concentraron en el Reino Unido, Francia, Alemania y EE. UU. (Pitarch y Blanes, 2016). 
atención a los ya conocidos mecanismos del origen ocupacional y educativo a la hora de estudiar la movilidad social.

No obstante, en la mayoría de trabajos hechos en nuestro país ha primado el análisis del conjunto de la población española o de la extranjera - o de ambas conjuntamente- y casi nunca se ha considerado como determinante la comunidad autónoma de origen del inmigrante. Cuando se ha hecho, en la mayoría de los casos, las diferentes procedencias territoriales se han reunido en un solo grupo. Por ejemplo, entre los trabajos pioneros, Pinilla de las Heras (1973) distinguía entre nativos — catalanes-y no nativos — no catalanes-. El problema de agrupar a todos los no nativos en una sola categoría era que no aportaba conclusiones teniendo en cuenta el efecto del origen regional, aspecto en el que podía haber profundizado, como se desprende del análisis que realizó en dos apartados en los que mostraba los periodos de admisión en empresas según las regiones de origen de los inmigrantes o la procedencia geográfica de los trabajadores en diferentes sectores de actividad económica. Carlota Solé realizó un estudio centrado en la migración andaluza (1981) y otro (1988) sobre el conjunto de los inmigrantes. En el primero de estos observó como la gran mayoría de andaluces que en su tierra tenían ocupaciones agrarias de nula o baja cualificación o que eran pequeños propietarios experimentaron una clara movilidad ocupacional ascendente, al igual, no obstante, que la que afectaba al conjunto de la población inmigrada y algo mayor a la experimentada por la población autóctona; pero en el segundo la autora no llegó a ninguna conclusión destacada sobre la movilidad. Asimismo, Pascual de Sans y Cardelús (1990), desde una perspectiva de retorno y partiendo de tres muestras, certificaron diferentes situaciones de movilidad ascendente o descendente, aunque quizás la constatación más importante fue el alto porcentaje de casos en que la situación socioocupacional anterior a la emigración se mantuvo sin cambios a lo largo del proceso migratorio, sobre todo en las personas que no habrían emigrado al extranjero. Con el nuevo siglo han aparecido nuevos trabajos que tratan la movilidad social en Cataluña (Casademont, 2016; Martínez y Marín, 2010, 2011; Recaño y Roig, 2003; Silvestre et al., 2015), pero solo el de Silvestre et al., centrado en la primera oleada migratoria, y el de Recaño y Roig, centrado en la segunda, distinguen como variable importante el origen de nacimiento de los diferentes inmigrantes internos a la hora de hablar de las trayectorias de movilidad social en Cataluña. Tanto en un trabajo como en otro, se manifiesta que ha existido en Cataluña una estructura de movilidad social en parte conformada por los diferentes orígenes de los inmigrantes, lo que respondería, también parcialmente, a una sociedad que se renueva constantemente por crecimiento migratorio, con flujos de perfil sociodemográfico diverso. Sin embargo, fueron Recaño y Roig (2003) los que apuntaron - precisamente utilizando la misma fuente que esta investigación- como, en los procesos de movilidad social para determinados grupos inmigrantes y en ciertos contextos socioeconómicos (Cataluña y País Vasco), la educación podría ser un activo no tan valorado a la hora de adquirir un estatus social elevado como en otros contextos (Madrid). 
Pero, pese a dichas aportaciones puntuales, este tema sigue sin suscitar mayoritariamente la atención de los investigadores de este ámbito. La disponibilidad de fuentes estadísticas específicas para su estudio explica en parte esta desatención. A pesar de que la Encuesta Sociodemográfica constituyó un hito en el panorama de las estadísticas de España, dio paso a escasos análisis sobre movilidad social (Carabaña, 1996, 1999; Recaño y Roig, 2003; Bernardi, 2007), aún y cuando por primera vez se recogía información biográfica de la vida laboral, educativa, migratoria y familiar de 158.264 individuos. Fue más aprovechada para el análisis demográfico de la fecundidad (Sánchez, 1998), la nupcialidad (Miret, 2001; Pérez, 2001), la emancipación juvenil (Miret, 2005; Hernández, 2002) o el estudio de las trayectorias residenciales (Susino, 2003; Módenes, 1998). Para el estudio de la movilidad social en uno o más territorios (Gobernado, 1994; Requena, 2010) o en todo el país (Echevarría, 1998; Marqués y Herrera-Usagre, 2010; Fachelli y López-Roldan, 2015) se han utilizado fuentes con muestras mucho más reducidas, como la Encuesta de Estructura, Conciencia y Biografía de Clase (Encuesta ECBC) o las diferentes encuestas de condiciones de vida (ECV), las cuales limitan el estudio de la movilidad social por origen de nacimiento de la población. Sí que para para la tercera oleada migratoria se ha contado con información de la Encuesta Nacional de Inmigrantes (ENI), realizada por el INE en el año 2007, que ha significado otro hito dentro del panorama estadístico español y ha destacado por proporcionar un gran número de estudios sobre diferentes dimensiones de la movilidad social de los extranjeros (Aysa-Lastra y Cachón, 2013; Caparrós y Navarro, 2010; Simón et al., 2010; Stanek y Veira, 2009), pero el tamaño muestral de esta encuesta tampoco ha permitido realizar una diferenciación detallada de los inmigrantes por origen ni una representatividad de los resultados a nivel de comunidades autónomas.

\section{Fuentes y metodología}

Este estudio ha recurrido, por un lado, a los microdatos de la Encuesta Sociodemográfica de 1991 (ESD91) y, de modo complementario, a los del censo de población de 1991, ambas fuentes elaboradas por el Instituto Nacional de Estadística (INE). La descripción de las principales características sociodemográficas de la población valenciana se realizó en base a los datos censales, mientras que para el resto de cálculos se utilizó la ESD91.

La ESD91 contiene información retrospectiva de más de 150.000 individuos de 10 años o más de edad residentes en España en 1991, es representativa por comunidades autónomas y ofrece información biográfica de la historia migratoria, laboral, educativa y familiar. No se han hecho desde entonces otras encuestas sociodemográficas de triple biografía en España, excepto la mencionada ENI, que solo contemplaba a la población nacida en el extranjero. A pesar de ser también única por el volumen total de la muestra, la submuestra de población nacida en la Comunidad Valenciana residente en Cataluña en 1991 es de solo 315. Pese a eso, Cataluña, después del País Valenciano, constituye la comunidad autónoma con mayor número de valencianos. 
Tabla 1. Población residente en Cataluña por territorios de nacimiento, 1991

\begin{tabular}{lrc}
\hline Lugar de nacimiento & Número de personas & $\%$ sobre población Cataluña \\
\hline Cataluña & 4.089 .365 & $67,5 \%$ \\
Andalucía & 867.098 & $14,3 \%$ \\
Extremadura & 170.387 & $2,8 \%$ \\
Castilla y León & 154.271 & $2,5 \%$ \\
Aragón & 148.700 & $2,5 \%$ \\
Castilla-La Mancha & 138.677 & $2,3 \%$ \\
Extranjero & 128.164 & $2,1 \%$ \\
Comunidad Valenciana & 79.763 & $1,3 \%$ \\
Galicia & 79.185 & $1,3 \%$ \\
Murcia, Región de & 77.335 & $1,3 \%$ \\
Madrid, Comunidad de & 41.002 & $0,7 \%$ \\
País Vasco & 17.533 & $0,3 \%$ \\
Asturias, Principado de & 15.784 & $0,3 \%$ \\
Navarra, Comunidad Foral de & 12.690 & $0,2 \%$ \\
Cantabria & 10.153 & $0,2 \%$ \\
Balears, Illes & 9.433 & $0,2 \%$ \\
Rioja, La & 8.621 & $0,1 \%$ \\
Ceuta, Melilla y otros territorios españoles & 6.802 & $0,1 \%$ \\
Canarias & 4.521 & $0,1 \%$ \\
Total & 6.059 .487 & $100,0 \%$ \\
\hline
\end{tabular}

Fuente: elaboración propia a partir del censo de 1991 (INE)

La población residente en hogares en Cataluña en 1991 era de 6.059.487 personas, de las cuales 79.763 eran nacidas en la Comunidad Valenciana (tabla 1). Para el estudio de la movilidad de los inmigrantes valencianos en comparación con la del resto de inmigrantes nacidos en otras comunidades autónomas, únicamente se distinguieron a aquellos grupos cuyo peso poblacional en el censo al menos representase un $1 \%$ de la población total residente. Esto es, aparte de valencianos, los andaluces, extremeños, castellanoleoneses, aragoneses, castellanomanchegos, gallegos y murcianos. El resto se descartó para el análisis y tampoco se consideró el formar con ellos un único grupo, ya que agruparía a regiones tan diversas entre sí como las Baleares, Madrid, Ceuta o la Rioja, por ejemplo.

El análisis de la movilidad social de los valencianos se realizó siempre en comparación con la movilidad de los inmigrantes de las comunidades autónomas de origen antes mencionadas. Se analizó la movilidad intrageneracional, por una parte, y la intergeneracional, por otra. Sin embargo, para estudiar la movilidad intrageneracional se utilizaron diferentes variables de la biografía laboral que para la intergeneracional. Con la primera se examinaron los cambios experimentados en la biografía laboral de los individuos que migraron entre los 25 y los 49 años, un año antes y diez después de hacerlo con el empleo de las variables sector de actividad y condición socioeconómica de la ESD91. Para ello se calcularon los valores tipificados y las pruebas de $\mathrm{Chi}^{2}$ para obte- 
ner la significación estadística y ver cómo estaban los inmigrantes de unos y otros orígenes - sobrerrepresentados o infrarrepresentados en las categorías de ambas variables - antes y después de la migración. Con la intergeneracional se comparó la situación del hijo o de la hija con la del padre cuando el primero o la primera tenía 16 años. En el estudio de este tipo de movilidad se optó por la variable categoría socioeconómica. No se contempló al colectivo femenino, no solo porque su movilidad social requiere de precauciones metodológicas específicas por la forma particular que tienen de relacionarse con el mercado laboral (Salido, 2002), sino también porque la ESD91 no ofrece información sobre la categoría socioeconómica de la madre ${ }^{11}$.

La categoría socioeconómica se agrupó ante la exigüidad de la muestra. La variable original distinguía trece categorías que expresaban cierta jerarquía vertical: «Empleadores expertos», «Empleadores no expertos», «Autónomos expertos», "Autónomos cualificados», "Autónomos no cualificados», "Cuadros expertos», «Cuadros no expertos», «Empleados expertos», «Empleados semiexpertos», «Empleados cualificados no manuales», «Empleados cualificados manuales», «Empleados no cualificados» y «No clasificables». Para la agrupación se intentó utilizar una perspectiva más neoweberiana que neomarxista (Domingo-Salvany et al., 2013) en la definición de las tres categorías sociales distinguidas, en especial, en relación con las categorías media y baja. Es decir, el principio rector de los grupos no es quién dispone de la propiedad de los medios de producción, sino una clasificación de las ocupaciones que trataría de definir cierta jerarquía de prestigio o renta. Cabe recordar que la categoría socioeconómica, a diferencia de las otras variables, deriva de la combinación de información de variables obtenidas directamente de las preguntas del cuestionario sobre educación y ocupación y que fue construida por el propio INE (Aranda, 1992). De manera que los "Autónomos no cualificados", aun siendo propietarios de los medios de producción, aparecen ubicados en la categoría baja, y los «Empleados cualificados manuales» o los «Empleados cualificados no manuales», así como los «Empleados expertos» y los «Empleados semiexpertos», no se agrupan en una categoría trabajadora en sentido amplio, sino también en la categoría media. Es decir, se siguió un modelo de clasificación más próximo a Goldthorpe que a Wright, en el que la categoría media se asemejaría al concepto de clases intermedias, definida como una "categoría heterogénea cuya característica común no es otra que la de situarse en la zona de la estructura social que registra mayor permeabilidad y movilidad social» (González, 1992: 107) o «zona de amortiguación social» (Echevarría, 1999), debido a la relativa permeabilidad que le caracteriza. Obviamente, la división en tres categorías planteó muchos dilemas. Además de cómo clasificar a los autónomos — que se resolvió en función de la cualificación-, la clasificación de los empleadores, sin disponer del número de empleados, también es discutible, porque seguramente

11. No se puede decir que el análisis de la movilidad social femenina sea una materia de escaso estudio, aunque lo cierto es que la mayoría de investigaciones clásicas sobre movilidad social y ocupacional han restringido su análisis a la población masculina ocupada (Salido, 1996). 
es una categoría muy heterogénea. Así pues, las doce categorías, excluyendo los «No clasificables», se reagruparon en tres: la alta, la media y la baja. La alta comprende las cuatro primeras categorías de la variable original; la baja, la de los empleados y autónomos no cualificados, y la media, el resto. Ahora bien, los criterios variaron ligeramente entre hijos y padres por diversos aspectos. En los primeros análisis se desveló no solo la insuficiencia de significación estadística para desagregación extensa, sino también que la trayectoria de los autónomos no cualificados (padre) y los empleados no cualificados (hijo) era una de las pocas significativamente sobrerrepresentadas en el conjunto y la única descendente en la movilidad intergeneracional de migrantes. Además, el $90 \%$ de los padres clasificados como «Autónomos no cualificados» se ocupaba en la agricultura, mientras que en el caso de los hijos solo lo hacía el 55\% (mientras que un 25\% aparece concentrado en la industria manufacturera y transportes). Así, ante la difícil tesitura de la ubicación de los autónomos, se optó por clasificar los no cualificados en el caso de los padres en la categoría baja y en el de los hijos autónomos, en la media, para controlar de algún modo la alteración del contenido de las ocupaciones y el significado de la categoría de autónomo entre padres e hijos.

Con la agrupación de estas tres categorías (baja, media y alta) se realizaron las tablas de movilidad intergeneracional de entrada y salida, se calcularon las tasas de movilidad absolutas o brutas totales — ascendente y descendente- y de inmovilidad, así como el indicador de Duncan (1955). Respecto a las tablas de movilidad, en las de entrada se representan el conjunto de personas con un mismo destino (hijo) que procede de distintas posiciones de origen (padre), mientras que en las de salida se representa el conjunto de personas de un mismo origen (padre) que termina en destinos diferentes (hijo). Las tasas de movilidad absoluta representan el total de individuos móviles, es decir, el total de individuos que muestran una categoría de origen (padre) distinta de la suya (hijo) sobre el total. La fórmula para calcularla es la siguiente:

$$
\operatorname{TAM} \frac{N-\sum_{i}^{K} n i i}{N}
$$

Donde $n^{\mathrm{ii}}$ define el número de casos de las celdas de la diagonal de las tablas de movilidad, aquellos individuos que presentan una categoría distinta a la de sus padres, y $N$ es el número total individuos. Se puede distinguir entre movilidad absoluta descendente y ascendente en función de si lo que se contabiliza son individuos que descienden de categoría laboral respecto a los padres o si ascienden. La tasa de inmovilidad absoluta o bruta relaciona el total de individuos que presentan la misma categoría que la de sus padres sobre el total. Todas estas medidas son brutas, ya que calculan la movilidad absoluta o real, sin distinguir entre: 1) aquella que responde al cambio estructural de las ocupaciones o de las categorías socioeconómicas que, con el paso del tiempo, muestran las economías en el transcurso de las generaciones de padres e hijos, 
y 2) la movilidad ligada a los cambios asociados entre las categorías de origen (padres) y de destino (hijos), neta de los efectos de tipo estructural.

El indicador de Duncan sigue siendo una medida bruta resumen que expresa el porcentaje de hijos que deberían cambiar de ocupaciones, sin reposición, para que la distribución del empleo en padres e hijos fuese idéntica (un valor nulo para este índice significa que la distribución de la ocupación de todos los hijos es idéntica a la distribución de los padres). Se expresa así:

$$
I D=\frac{1}{2} \sum\left|\frac{P_{i}}{P}-\frac{H i}{H}\right|
$$

Donde $P i$ y $H i$ son el número de padres y de hijos en la ocupación $i$, respectivamente, y $P$ y $H$ son el total de padres y de hijos ocupados, respectivamente.

Además, para captar las oportunidades relativas de movilidad, es decir, la movilidad neta de los efectos de cambio estructural, se ha calculado otro indicador, las razones de momios u odds ratio (Carabaña, 1999). Estas se calculan entre las distintas combinaciones de categorías de origen (padres) y destino (hijos) a partir de las frecuencias de la tabla de origen y destino. Dicho indicador expresa el cociente entre la probabilidad de que un individuo tenga una categoría $j$ teniendo el padre una categoría $j$ y su complemento:

$$
\frac{P i j}{1-P i j}
$$

De modo que las razones de momios comparan, por ejemplo, la probabilidad que tiene un individuo de origen de categoría media (padre) de tener una categoría baja (hijo), en contraposición con otro de origen de categoría alta (categoría de referencia) de reproducir su situación.

Seguidamente, se ha realizado un modelo de regresión binomial para los individuos de origen de categoría social baja en el que la variable dependiente era la probabilidad de experimentar una ascensión frente a la inmovilidad tomando como referencia a los inmigrantes de origen valenciano, y un modelo multinomial para los individuos de categoría de origen media y alta en los que la variable dependiente era la probabilidad de experimentar un ascenso o un descenso social, en relación con la inmovilidad de los inmigrantes de categoría media de origen valenciano (categoría de referencia). Estos modelos nos permitieron controlar el efecto de la edad.

\section{Los valencianos en 1991 en Cataluña. Principales características sociodemográficas}

Los inmigrantes de origen valenciano que residían en 1991 en Cataluña —más de 79.000 personas - constituían el grupo de población que presentaba una edad 
Figura 1. Pirámide de la población valenciana residente en Cataluña, 1991
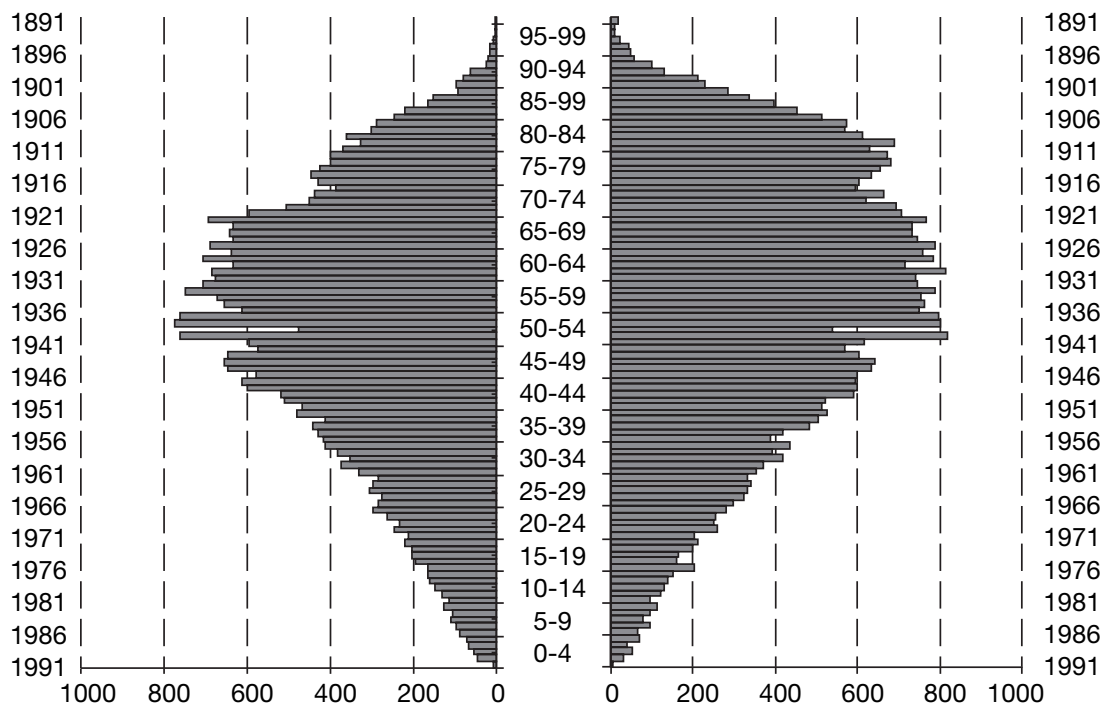

Fuente: elaboración propia a partir del censo de 1991 (INE)

media más elevada (57 años) después de los murcianos (60 años) y muy por encima de la que presentaban los orígenes mayoritarios de entonces ${ }^{12}$. Se trataba de una población envejecida no solo en relación con el resto de inmigrantes, sino también respecto a los nativos, que registraban en esa fecha una edad media de 33 años.

La pirámide de población nos aproxima al historial migratorio de ese momento (figura 1), al reflejar una población que tenía entre 40 y 70 años de edad en su mayoría (un 58\%) y que migró en su mayor parte en las décadas de 1950 y 1960 (un 42\% del total llegó entre 1950 y 1969). El análisis de las décadas de llegada de la población de origen valenciano en 1991 nos muestra cómo también era posible localizar entonces estratos de la primera oleada migratoria del siglo XX — la correspondiente a la década de 1920 principalmente (figura 2$)^{13}$ - No es de extrañar, por tanto, que hasta un tercio de la población valenciana en 1991 (34\%) fuese mayor de 64 años.

Además de esto, la población valenciana residente en Cataluña en 1991 se caracterizaba por las siguientes tres particularidades.

En primer lugar, al existir más población valenciana entonces que en el presente, había un destacado número de municipios valencianos que aportaban

12. Los andaluces, por ejemplo, tenían una media de edad de 48 años, y los extremeños, de 47 años.

13. Gran parte de la población valenciana registrada en 1930 en el padrón habría fallecido años antes de realizarse el censo de 1991 o la Encuesta Sociodemográfica, al tratarse de una inmigración muy antigua, incluso de finales del siglo XIX (Oyón et al., 2001), por lo que su registro en el censo de 1991 es muy escaso. 
Figura 2. Población valenciana residente en Cataluña por periodos de llegada, 1991

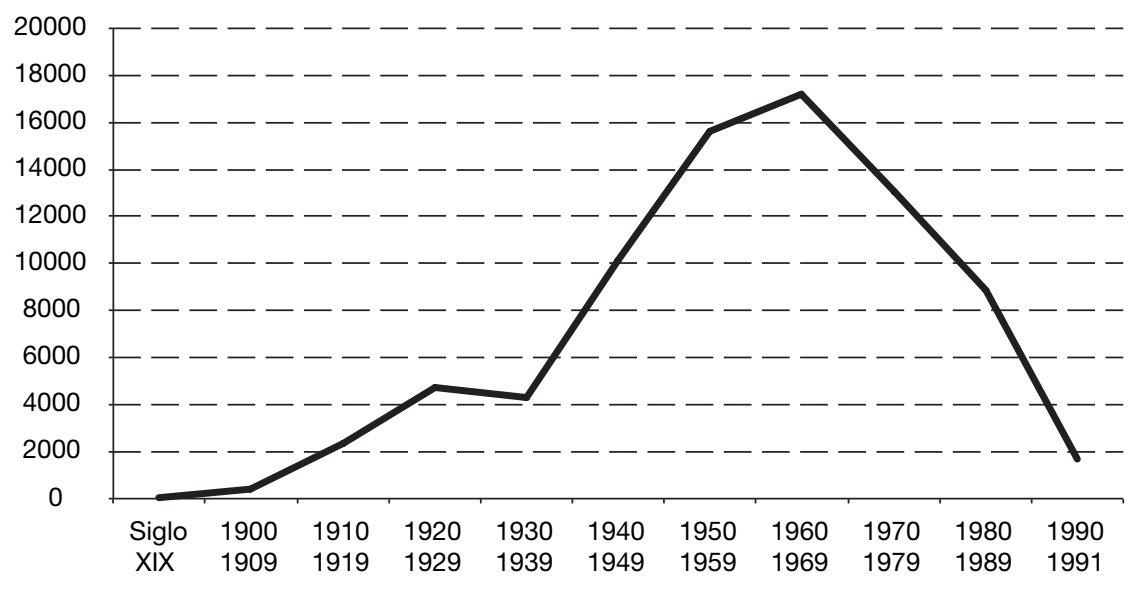

Fuente: elaboración propia a partir del censo de 1991 (INE)

efectivos a Cataluña que actualmente no encontraríamos de manera tan destacada en los últimos datos del padrón continuo. Se trata de núcleos del interior valenciano que sufrieron un gran éxodo rural que se inició a principios del siglo XX y se intensificó a partir de los años cincuenta. Algunos de ellos no consiguieron recuperarse (Hernández, 2004), sin embargo, otros, a pesar de haber mantenido los movimientos emigratorios con altibajos, consiguieron mitigar los efectos del éxodo poblacional e incluso obtener una cierta estabilidad demográfica, gracias, en parte, al desarrollo de alguna actividad económica ${ }^{14}$.

En segundo lugar, aunque una primera mirada de la distribución de la población valenciana en Cataluña pareciese indicarnos que los valencianos se distribuían preferentemente en las ciudades que albergaban a más de 1.000 valencianos cada una y en torno a ellas (véase el mapa 1), esto no era exactamente así. Un análisis más profundo de su concentración realizado a través del cociente de localización (CL) ${ }^{15}$ nos señala que en 1991 solo existían dos zonas

14. Los municipios de Requena, Utiel (Piqueras y Sanchís, 1986), Vila-Real, Burriana (Romero y Domingo, 1979) o Villena (Sebastià, 1997) serían algunos ejemplos de este último caso.

15. El cociente de localización $(C L)$ es uno de los indicadores metodológicos más sencillos que existe y que sirve para determinar el grado de concentración de un colectivo o de una actividad económica en un área determinada en relación con el conjunto. Suele ser muy utilizado tanto en geografía como en economía y demografía. Su fórmula se puede resumir de la siguiente manera:

$$
C L i=(v i / t i) /(V / T)
$$

Donde vi y ti representan a la población inmigrante que estudiamos y a la población total en un área determinada (en nuestro caso, municipios), y $V$ y $T$ representan a la población total inmigrante que estudiamos y al conjunto de la población total de todo el territorio (en nuestro caso, Cataluña). Si el resultado de este indicador es igual a 1, nos indica que el municipio tiene una concentración normal respecto al total de Cataluña. Si el resultado es 
Mapa 1. Distribución de la población nacida en el País Valenciano residente en Cataluña por municipios

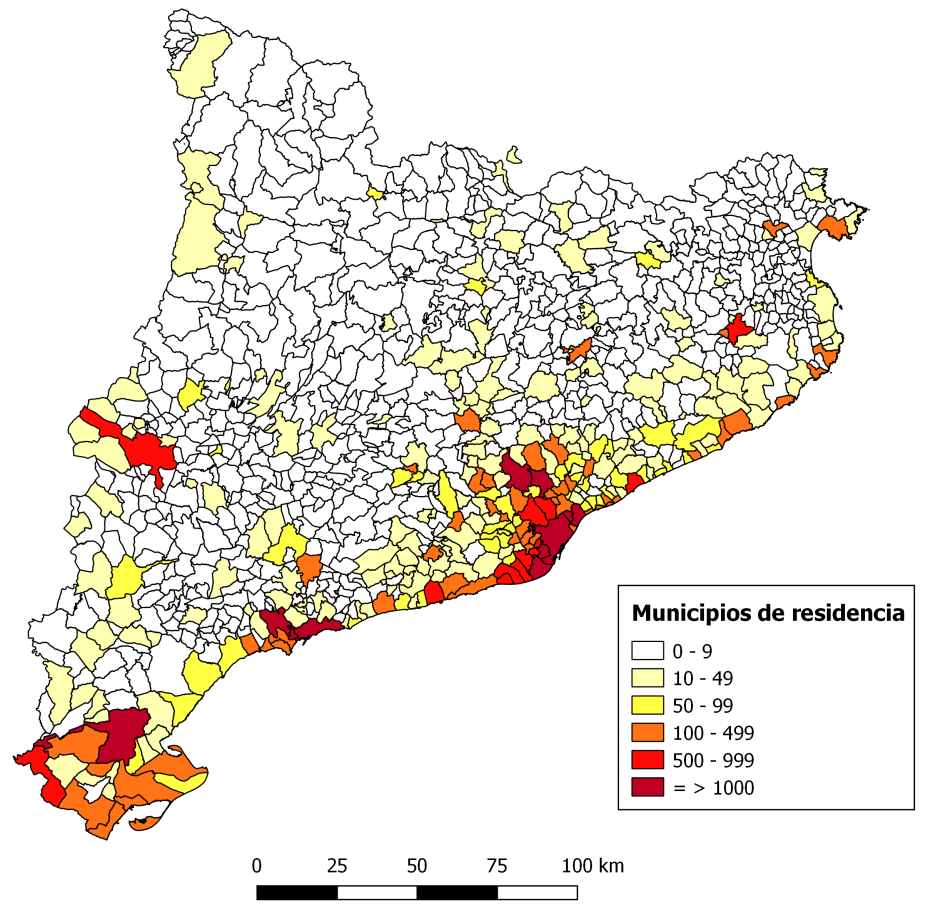

Fuente: elaboración propia a partir del censo de 1991 (INE)

de elevada concentración valenciana: la localizada en torno al Área Metropolitana de Barcelona, por una parte, y la situada en torno a les Terres de l'Ebre, por otra parte (véase el mapa 2). Sí que es cierto que una tercera área está emergiendo en torno a la ciudad de Tarragona, pero no con la importancia que adquirirá en el siglo XXI, tras la masiva llegada de docentes a esta área ${ }^{16}$.

superior a 1, la concentración en este municipio será superior a la del resto de municipios, y si es inferior nos indica lo contrario, que los inmigrantes de un determinado municipio están infrarrepresentados ahí. Para la representación de nuestros cálculos, sin embargo, hemos utilizado las mismas categorías de clasificación que Brown y Chung (2006), los cuales consideran que una relación entre 0,85 y 1,20 indica una concentración neutral, mientras que por encima hablaríamos de sobrerrepresentación, y por debajo, de infrarrepresentación. Cabe decir que hemos descartado las poblaciones donde viven menos de 5 personas nacidas en el País Valenciano, para no distorsionar los resultados.

16. Y es que la tercera área, que se ubica en un eje que comprende Reus, Tarragona y alrededores, estaría íntimamente relacionada con la reciente migración valenciana más cualificada, principalmente de personas vinculadas al mundo de la enseñanza, ya que dicho eje abarca justamente la zona territorial del Departament d'Ensenyament de Tarragona (Domingo y Pitarch, 2015). 
Mapa 2. Concentración de la población nacida en el País Valenciano residente en Cataluña según municipios

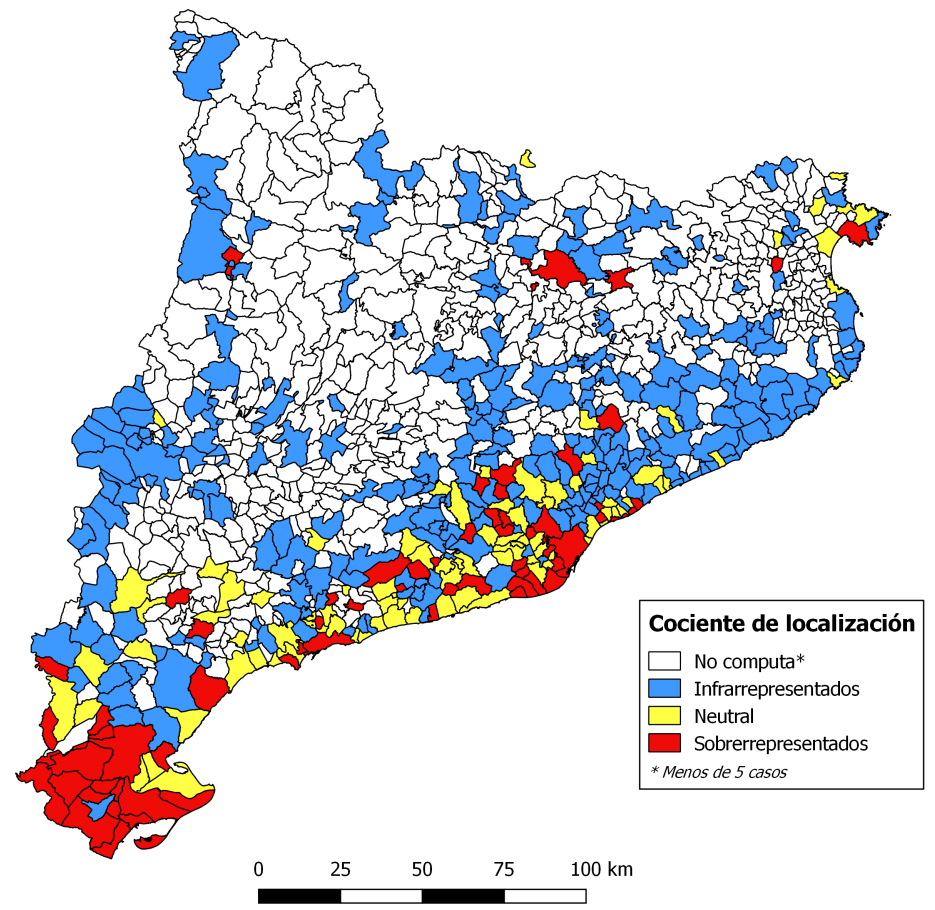

Fuente: elaboración propia a partir del censo de 1991 (INE)

Y en tercer y último lugar, en el año 1991 el sector ocupacional que aglutinaba a más valencianos era el de los artesanos y trabajadores cualificados de las industrias manufactureras y la construcción, con casi un 19\%. Le seguían a poca distancia el de los técnicos y profesionales de apoyo, con un 16\%, y el de los operadores de instalaciones y maquinaria y montadores, con un 15\%. Por tanto, no había una destacada mayoría que se dedicara al ámbito de la enseñanza, la investigación o las ciencias de la salud como pasa ahora (Domingo y Pitarch, 2015), sino que existía una mayor heterogeneidad ocupacional.

Además de esto, una variable que hay que tener presente cuando se habla de procesos de movilidad social es el grado de conocimiento y uso de la lengua de la sociedad de acogida. Pues bien, el conjunto de la inmigración valenciana - parte de la cual compartía su lengua con la sociedad catalana - mostraba unos índices muy elevados en el conocimiento y uso del catalán (figura 3), lo que les situaría, sin ninguna duda, con una ligera ventaja respecto al resto de inmigrantes de cara a un posible ascenso de estatus.

La afinidad cultural y lingüística, la mayor antigüedad de los stocks, una inmigración con mayor componente individual que la de otras comunida- 
Figura 3. Grado de conocimiento del catalán de la población residente en Cataluña por lugar de nacimiento, 1991

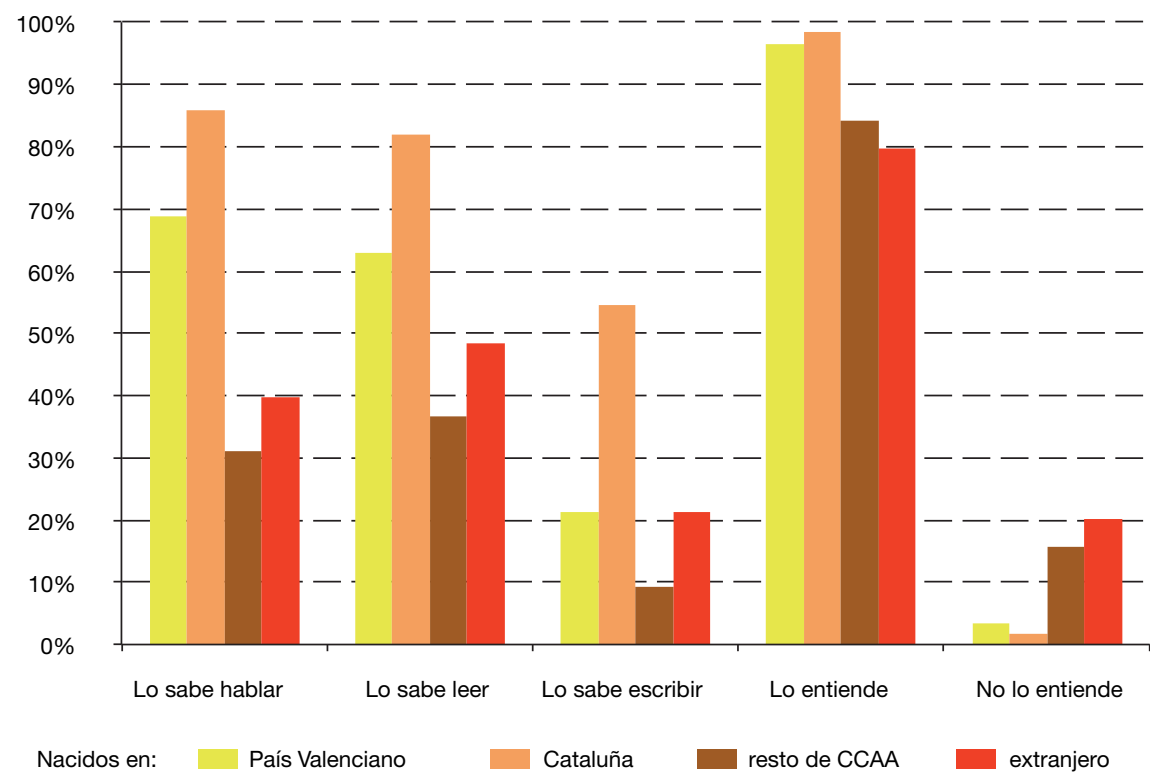

Fuente: elaboración propia a partir del censo de 1991 (INE)

Figura 4. Composición por origen de las parejas de la población inmigrante según la comunidad autónoma de nacimiento en Cataluña, 1991

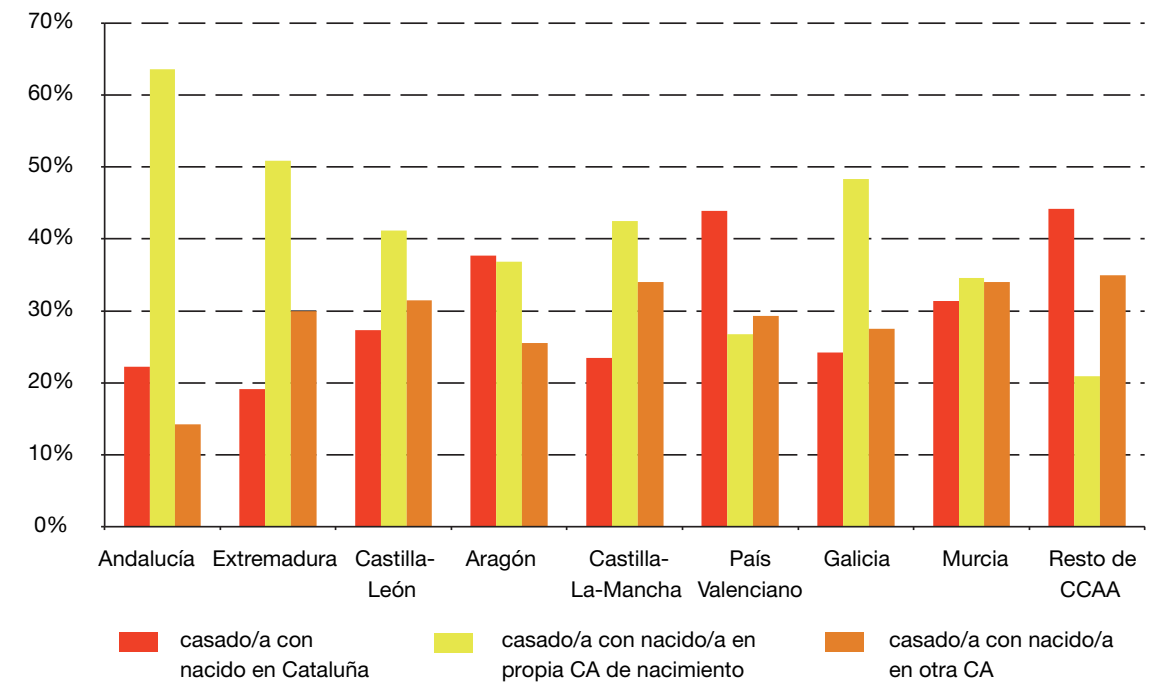

Fuente: elaboración propia a partir del censo de 1991 (INE) 
des autónomas de origen, una menor capacidad de elección en el mercado matrimonial entre sus propios congéneres o un grado más elevado de integración podrían explicar el relativamente alto porcentaje de matrimonios entre catalanes y valencianos en 1991. Solo los aragoneses, con un 38\% de parejas con algún catalán o catalana, se aproximaban a los valores de los valencianos, un 44\% (figura 4). Los valencianos eran, por otra parte, los que menos estaban casados con ciudadanos de su misma comunidad autónoma (un $27 \%$ de las parejas), seguidos por los murcianos, pero ya con un $34 \%$.

\section{Análisis y resultados}

\subsection{Movilidad intrageneracional}

Antes de adentrarnos en el análisis, sería conveniente saber las tasas de actividad de los valencianos que residían en 1991 en Cataluña. Los hombres que habían migrado entre los 20 y los 49 años de edad presentaban una tasa de ocupación del $79 \%$ el año previo a migrar, mientras que la de las mujeres era del $47 \%$; diez años después, los porcentajes correspondientes eran de un $92 \%$ en los hombres y un 36\% en las mujeres. En general, todos los orígenes incrementaron la ocupación masculina y disminuyeron la femenina, pero las valencianas lo hicieron en mayor medida que el resto.

A continuación, tras calcular los valores tipificados y realizar las correspondientes pruebas de $\mathrm{Chi}^{2}$, se presentan las tablas de doble entrada de los inmigrantes por comunidad autónoma de nacimiento y por sector de actividad en ambos momentos de la biografía laboral, diferenciando las mujeres de los hombres. Los valores tipificados por debajo de $-1,96$ indican que el sector de actividad de la comunidad autónoma correspondiente está infrarrepresentado («Infra») respecto al total, si están por encima de 1,96, que está sobrerrepresentado («Sobre»), y si están entre $-1,96$ y 1,96, que no tiene un peso diferente («No dif.»). Cuando los valores esperados están por debajo de 5, las celdas se muestran vacías por no tener significación estadística.

En la etapa previa a la migración, lo más destacable es que los valencianos no presentan un perfil diferenciado estadísticamente significativo del conjunto de migrantes, como tampoco lo hacen los murcianos ni los castellanomanchegos. Los andaluces se dedican al sector de la construcción en una proporción mayor de la esperada y los castellanoleoneses y los gallegos trabajan en el sector servicios. La infrarrepresentación en servicios de la ocupación se presenta entre los andaluces y los extremeños y en la construcción entre los aragoneses y castellanoleoneses. Estos últimos, además, están infrarrepresentados en el sector de la agricultura y sobrerrepresentados en la industria.

Las mujeres valencianas tampoco presentan un perfil estadísticamente diferente del conjunto antes de migrar y sí que destacan, en cambio, las andaluzas, con su mayor peso en la agricultura y menor en los servicios, o las castella- 
Tabla 2. Test de $\mathrm{Chi}^{2}$, distribución del sector económico al que se dedicaban un año antes de migrar los migrantes que vivían en Cataluña, varones y mujeres, 1991

\begin{tabular}{|c|c|c|c|c|c|c|c|c|}
\hline \multicolumn{9}{|c|}{ Hombres } \\
\hline & \multicolumn{2}{|c|}{ Andalucía } & \multicolumn{2}{|c|}{ Aragón } & \multicolumn{2}{|c|}{ Castilla-La Mancha } & \multicolumn{2}{|c|}{ Castilla y León } \\
\hline Agricultura, ganadería y pesca & 1,5 & No dif. & $-1,1$ & No dif. & 1,7 & No dif. & $-3,4$ & Infra \\
\hline Industria & -1 & No dif. & 1,1 & No dif. & 0,6 & No dif. & 0,4 & No dif. \\
\hline Construcción & 4,7 & Sobre & $-2,1$ & Infra & $-1,6$ & No dif. & $-3,5$ & Infra \\
\hline Servicios & -2 & Infra & 0,7 & No dif. & $-1,5$ & No dif. & 3,5 & Sobre \\
\hline \multirow[t]{2}{*}{ Servicio doméstico } & - & - & - & - & - & - & - & \\
\hline & \multicolumn{2}{|c|}{ País Valenciano } & \multicolumn{2}{|c|}{ Extremadura } & \multicolumn{2}{|c|}{ Galicia } & \multicolumn{2}{|c|}{ Murcia } \\
\hline Agricultura, ganadería y pesca & $-0,5$ & No dif. & 1,8 & No dif. & -1 & No dif. & $-0,7$ & No dif. \\
\hline Industria & $-0,1$ & No dif. & 0,9 & No dif. & $-1,4$ & No dif. & $-0,3$ & No dif. \\
\hline Construcción & $-1,9$ & No dif. & 0,6 & No dif. & 0 & No dif. & $-0,4$ & No dif. \\
\hline Servicios & 1 & No dif. & $-2,5$ & Infra & 2 & Sobre & 1,8 & No dif. \\
\hline Servicio doméstico & - & - & - & - & - & - & - & - \\
\hline \multicolumn{9}{|c|}{ Mujeres } \\
\hline & \multicolumn{2}{|c|}{ Andalucía } & \multicolumn{2}{|c|}{ Aragón } & \multicolumn{2}{|c|}{ Castilla-La Mancha } & \multicolumn{2}{|c|}{ Castilla y León } \\
\hline Agricultura, ganadería y pesca & 3,3 & Sobre & $-1,6$ & No dif. & $-1,5$ & No dif. & $-1,6$ & No dif. \\
\hline Industria & -1 & No dif. & 0,7 & No dif. & $-1,9$ & No dif. & 0,2 & No dif. \\
\hline Construcción & - & - & - & - & - & - & - & - \\
\hline Servicios & $-3,4$ & Infra & 1,2 & No dif. & 0,8 & No dif. & 2,3 & Sobre \\
\hline \multirow[t]{2}{*}{ Servicio doméstico } & 0,6 & No dif. & -1 & No dif. & 0,4 & No dif. & 0,4 & No dif. \\
\hline & \multicolumn{2}{|c|}{ País Valenciano } & \multicolumn{2}{|c|}{ Extremadura } & \multicolumn{2}{|c|}{ Galicia } & \multicolumn{2}{|c|}{ Murcia } \\
\hline Agricultura, ganadería y pesca & $-0,9$ & No dif. & $-1,3$ & No dif. & 1,5 & No dif. & $-0,4$ & No dif. \\
\hline Industria & 0,7 & No dif. & $-0,4$ & No dif. & $-0,9$ & No dif. & 4,4 & Sobre \\
\hline Construcción & - & - & - & - & - & - & - & - \\
\hline Servicios & 0,8 & No dif. & 0,7 & No dif. & 0,4 & No dif. & $-0,2$ & No dif. \\
\hline Servicio doméstico & $-0,2$ & No dif. & 0,1 & No dif. & 0,3 & No dif. & $-1,7$ & No dif. \\
\hline
\end{tabular}

Fuente: elaboración propia a partir de la ESD91 (INE)

noleoneses y las murcianas, sobrerrepresentadas en el sector servicios y en la industria, respectivamente.

Los valencianos, después de la migración y a diferencia que antes, sí se distinguen del conjunto con una ocupación menor en la construcción y más alta en servicios. Los andaluces, los aragoneses, los extremeños, los gallegos y los castellanoleoneses siguen despuntando en los mismos sectores antes y después de migrar, aunque los últimos ahora también lo hacen en la industria. Los murcianos, al contrario, son los que tienen una distribución menos diferenciada, tanto antes como después de migrar, y se parecen más a los migrantes castellanomanchegos, extremeños y gallegos, aunque los dos primeros se distinguen después de migrar por una infrarrepresentación en los servicios, mientras que en los gallegos ocurre lo contrario, puesto que destaca su mayor ocupación en este sector. 
Tabla 3. Test de $\mathrm{Chi}^{2}$, distribución del sector económico al que se dedicaban diez años después de migrar los migrantes que vivían en Cataluña, varones y mujeres, 1991

\begin{tabular}{|c|c|c|c|c|c|c|c|c|}
\hline \multicolumn{9}{|c|}{ Hombres } \\
\hline \multirow[b]{2}{*}{ Agricultura, ganadería y pesca } & \multicolumn{2}{|c|}{ Andalucía } & \multicolumn{2}{|c|}{ Aragón } & \multicolumn{2}{|c|}{ Castilla-La Mancha } & \multicolumn{2}{|c|}{ Castilla y León } \\
\hline & 0,6 & No dif. & $-1,1$ & No dif. & 1,9 & No dif. & $-3,6$ & Infra \\
\hline Industria & $-2,4$ & Infra & 1,6 & No dif. & 0,9 & No dif. & 2 & Sobre \\
\hline Construcción & 4,9 & Sobre & $-2,6$ & Infra & $-0,8$ & No dif. & $-3,2$ & Infra \\
\hline Servicios & $-3,2$ & Infra & 1,5 & No dif. & $-2,1$ & Infra & 4,4 & Sobre \\
\hline \multirow[t]{2}{*}{ Servicio doméstico } & - & - & - & - & - & - & - & - \\
\hline & \multicolumn{2}{|c|}{ País Valenciano } & \multicolumn{2}{|c|}{ Extremadura } & \multicolumn{2}{|c|}{ Galicia } & \multicolumn{2}{|c|}{ Murcia } \\
\hline Agricultura, ganadería y pesca & 0,2 & No dif. & 1,3 & No dif. & $-0,4$ & No dif. & 0,5 & No dif. \\
\hline Industria & $-0,3$ & No dif. & 0,8 & No dif. & $-0,8$ & No dif. & $-0,7$ & No dif. \\
\hline Construcción & $-2,8$ & Infra & 1,2 & No dif. & $-1,1$ & No dif. & $-0,6$ & No dif. \\
\hline Servicios & 3,4 & Sobre & $-2,7$ & Infra & 2,6 & Sobre & 0,8 & No dif. \\
\hline Servicio doméstico & - & - & - & - & - & - & - & - \\
\hline \multicolumn{9}{|c|}{ Mujeres } \\
\hline & \multicolumn{2}{|c|}{ Andalucía } & \multicolumn{2}{|c|}{ Aragón } & \multicolumn{2}{|c|}{ Castilla-La Mancha } & \multicolumn{2}{|c|}{ Castilla y León } \\
\hline Agricultura, ganadería y pesca & 1,3 & No dif. & $-1,3$ & No dif. & 0 & No dif. & $-1,1$ & No dif. \\
\hline Industria & 0,3 & No dif. & -1 & No dif. & $-0,3$ & No dif. & $-0,5$ & No dif. \\
\hline Construcción & - & - & - & - & - & - & - & - \\
\hline Servicios & $-2,4$ & Infra & 2,4 & Sobre & $-1,8$ & No dif. & 4,1 & Sobre \\
\hline \multirow[t]{2}{*}{ Servicio doméstico } & 2,8 & Sobre & $-1,1$ & No dif. & $-0,9$ & No dif. & $-1,6$ & No dif. \\
\hline & \multicolumn{2}{|c|}{ País Valenciano } & \multicolumn{2}{|c|}{ Extremadura } & \multicolumn{2}{|c|}{ Galicia } & \multicolumn{2}{|c|}{ Murcia } \\
\hline Agricultura, ganadería y pesca & $-0,5$ & No dif. & $-0,4$ & No dif. & - & - & - & - \\
\hline Industria & $-0,1$ & No dif. & 0,4 & No dif. & $-0,9$ & No dif. & 2,3 & Sobre \\
\hline Construcción & - & - & - & - & - & - & - & - \\
\hline Servicios & $-0,3$ & No dif. & $-1,4$ & No dif. & 1,1 & No dif. & 0,3 & No dif. \\
\hline Servicio doméstico & $-0,8$ & No dif. & $-0,1$ & No dif. & 1,2 & No dif. & -2 & Infra \\
\hline
\end{tabular}

Fuente: elaboración propia a partir de la ESD91 (INE)

El perfil relativo de la distribución de la ocupación entre las mujeres inmigrantes por origen cambia menos que el de los hombres antes y después de migrar: las valencianas, al igual que las catellanomanchegas, las gallegas y las extremeñas, presentan una distribución de la ocupación que podemos decir que no se diferencia del resto de población antes y después de migrar. Por el contrario, las proporciones de mujeres andaluzas en el sector agrícola se revelan superiores antes de migrar, pero no después, y viceversa respecto a la ocupación en servicio doméstico, que concentra mayor ocupación que el conjunto. La sobrerrepresentación de las aragonesas y de las castellanoleonesas se da en servicios, mientras que las murcianas son las únicas en la que se aprecia una sobrerrepresentación en la industria antes y después de migrar.

En las tablas 4 y 5 se presentan los mismos datos para la situación profesional. Los oriundos del País Valenciano sobresalen por una menor 
Tabla 4. Test de $\mathrm{Chi}^{2}$, distribución de la situación profesional a la que se dedicaban un año antes de migrar los migrantes que vivían en Cataluña, varones y mujeres, 1991

\begin{tabular}{|c|c|c|c|c|c|c|c|c|}
\hline \multicolumn{9}{|c|}{ Hombres } \\
\hline & \multicolumn{2}{|c|}{ Andalucía } & \multicolumn{2}{|c|}{ Aragón } & \multicolumn{2}{|c|}{ Castilla-La Mancha } & \multicolumn{2}{|c|}{ Castilla y León } \\
\hline Empresario & $-3,6$ & Infra & 4,1 & Sobre & 0,6 & No dif. & $-0,9$ & No dif. \\
\hline Ayuda familiar o coop. & -1 & No dif. & -1 & No dif. & 0,7 & No dif. & 0,2 & No dif. \\
\hline Asalariado & 5,7 & Sobre & $-2,7$ & Infra & $-1,2$ & No dif. & $-2,6$ & Infra \\
\hline \multirow[t]{2}{*}{ Funcionario } & $-1,4$ & No dif. & 0,2 & No dif. & 0,1 & No dif. & 1,3 & No dif. \\
\hline & \multicolumn{2}{|c|}{ País Valenciano } & \multicolumn{2}{|c|}{ Extremadura } & \multicolumn{2}{|c|}{ Galicia } & \multicolumn{2}{|c|}{ Murcia } \\
\hline Empresario & 1,1 & No dif. & 0,9 & No dif. & 0,9 & No dif. & 0,1 & No dif. \\
\hline Ayuda familiar o coop. & $-0,2$ & No dif. & 0,6 & No dif. & 0,1 & No dif. & 1,7 & No dif. \\
\hline Asalariado & $-2,8$ & Infra & 0 & No dif. & $-1,2$ & No dif. & $-0,4$ & No dif. \\
\hline Funcionario & - & - & $-0,5$ & & No dif. & - & - & - \\
\hline \multicolumn{9}{|c|}{ Mujeres } \\
\hline & \multicolumn{2}{|c|}{ Andalucía } & \multicolumn{2}{|c|}{ Aragón } & \multicolumn{2}{|c|}{ Castilla-La Mancha } & \multicolumn{2}{|c|}{ Castilla y León } \\
\hline Empresario & $-0,7$ & No dif. & - & - & - & - & $-1,5$ & No dif. \\
\hline Ayuda familiar o coop. & 1,1 & No dif. & $-2,1$ & Infra & 0,3 & No dif. & $-0,4$ & No dif. \\
\hline Asalariado & $-0,4$ & No dif. & 0 & No dif. & $-1,1$ & No dif. & 0,5 & No dif. \\
\hline \multirow[t]{2}{*}{ Funcionario } & $-2,3$ & Infra & - & - & - & - & - & - \\
\hline & \multicolumn{2}{|c|}{ País Valenciano } & \multicolumn{2}{|c|}{ Extremadura } & \multicolumn{2}{|c|}{ Galicia } & \multicolumn{2}{|c|}{ Murcia } \\
\hline Empresario & - & - & - & - & - & - & - & - \\
\hline Ayuda familiar o coop. & 0,4 & No dif. & 0,3 & No dif. & 1,6 & No dif. & $-2,5$ & Infra \\
\hline Asalariado & 0,4 & No dif. & 0,4 & No dif. & $-1,9$ & No dif. & 2,8 & Sobre \\
\hline Funcionario & - & - & - & - & - & - & - & - \\
\hline
\end{tabular}

Fuente: elaboración propia a partir de la ESD91 (INE)

proporción de asalariados antes y después de migrar, y solo después de la migración destacan también por una elevada ocupación en el empresariado. Los aragoneses destacan con un perfil parecido e inverso al de los andaluces con infrarrepresentación en la situación de empresario y sobrerrepresentación entre los asalariados, tanto antes como después de la migración. Solo los castellanoleoneses presentan una sobrerrepresentación en la situación de funcionario después de la migración. Las mujeres inmigrantes en su situación profesional resultan menos diferencias por comunidad autónoma de nacimiento que los hombres y las de la Comunidad Valenciana no presentan diferencias con el conjunto. Solo las aragonesas y las murcianas aparecen antes de migrar significativamente con menor proporción en la situación de ayudas familiares, aunque en las segundas es menor la concentración tras la migración. Las andaluzas se distinguen antes y después con menor peso significativo de las funcionarias y más en la de ayuda familiar después de migrar. Las murcianas también concentran más trabajo asalariado a los diez años de llegar a Cataluña. 
Tabla 5. Test de $\mathrm{Chi}^{2}$, distribución de la situación profesional a la que se dedicaban diez años después de migrar los migrantes que vivían en Cataluña, varones y mujeres, 1991

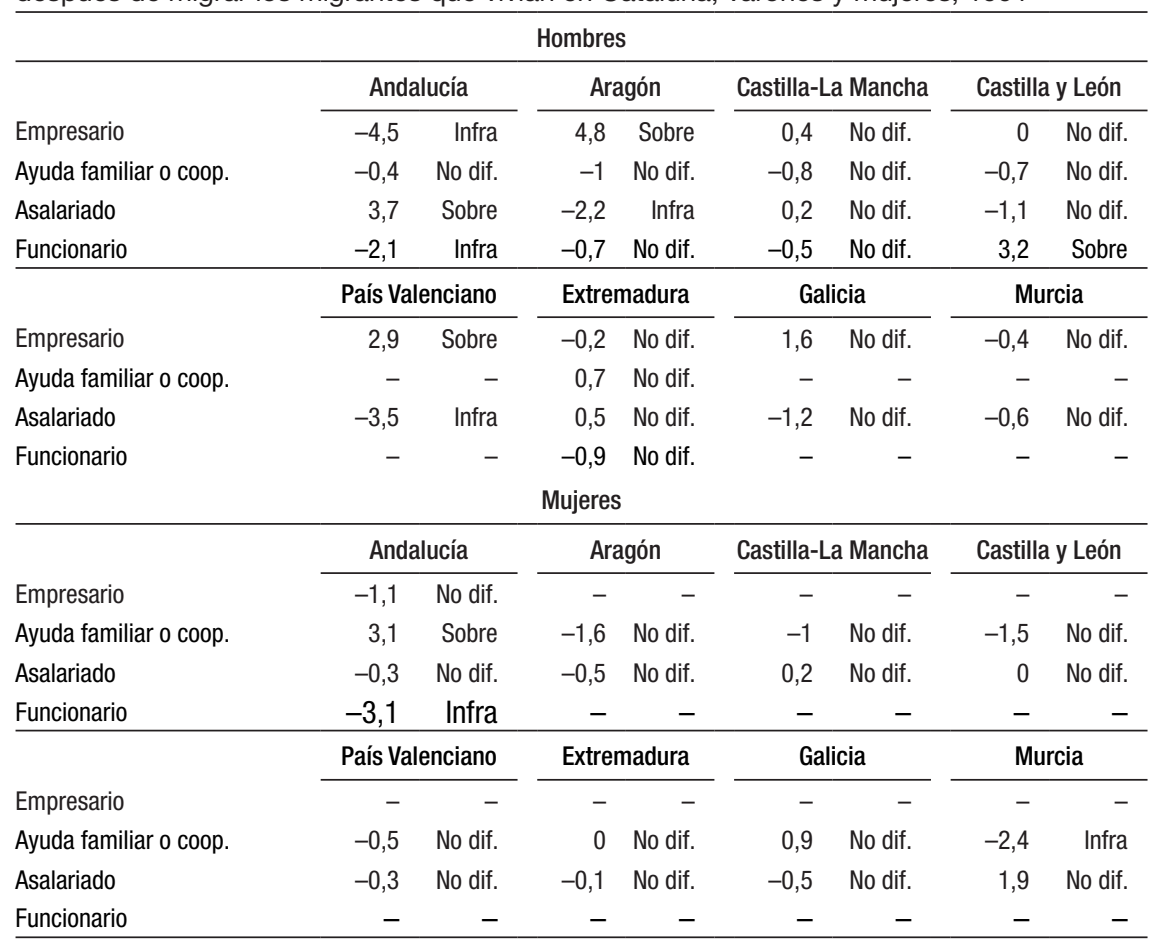

Fuente: elaboración propia a partir de la ESD91 (INE)

\subsection{Movilidad intergeneracional}

En la tabla 6 se muestran las tasas de movilidad absoluta intergeneracional de la categoría socioeconómica de los inmigrantes de 30 a 64 años residentes en Cataluña en 1991 —en comparación con la de sus padres cuando estos tenían 16 años-, según la comunidad autónoma de nacimiento del inmigrante y el indicador de Duncan. Los nacidos en la Comunidad Valenciana, con una tasa del 56\%, registran el máximo valor de movilidad ascendente. Seguidamente encontramos a los de Castilla y León, con una tasa en torno al 54\%, y a los de Murcia, con una del 53\%. En cambio, los inmigrantes con menor tasa de movilidad ascendente son los de Andalucía y Galicia, con porcentajes similares. Andalucía, además, junto a Castilla-La Mancha, es la comunidad con una mayor tasa de inmovilidad, con un $43 \%$. En la movilidad descendente destaca con el máximo porcentaje de Galicia y el mínimo de Castila y León. $\mathrm{El}$ indicador de Duncan resume estos efectos brutos señalando unos valores mínimos en Andalucía y Extremadura y unos máximos en el País Valenciano y en Castilla y León. De esta manera, hasta un $47 \%$ de la población masculina 
Tabla 6. Tasas de movilidad absoluta e indicador de Duncan. Movilidad intergeneracional por categoría socioeconómica (porcentajes) según la comunidad autónoma de nacimiento, varones, 1991

\begin{tabular}{lcccc}
\hline & Ascendente & Descendente & Inmovilidad & Índice Duncan \\
\hline Andalucía & 43,90 & 12,87 & 43,23 & 31,76 \\
Aragón & 49,70 & 12,16 & 38,13 & 35,00 \\
Castilla-La Mancha & 46,28 & 10,27 & 43,45 & 35,05 \\
Castilla y León & 54,65 & 8,75 & 36,60 & 42,58 \\
País Valenciano & 55,92 & 12,83 & 31,25 & 46,93 \\
Extremadura & 49,69 & 14,12 & 36,19 & 33,15 \\
Galicia & 44,53 & 19,84 & 35,63 & 33,27 \\
Murcia & 52,84 & 15,22 & 31,94 & 39,92 \\
Resto CCAA & 32,47 & 20,16 & 47,37 & 16,24 \\
Total & 46,28 & 13,12 & 40,61 & 33,17 \\
\hline
\end{tabular}

Fuente: elaboración propia a partir de la ESD91 (INE)

valenciana de 30-64 años y un 42\% de la castellanoleonesa tendría que cambiar de categoría socioeconómica para repetir la distribución de sus padres. En cambio, solo un 32\% de los andaluces y un 33\% de los extremeños y los gallegos tendrían que hacerlo.

A nivel descriptivo se presenta el detalle de las tablas de movilidad de salida (u outflow) y de entrada (o inflow) que incluyen también efectos absolutos y relativos de movilidad. Las primeras describen las posibilidades que tienen los inmigrantes de las distintas comunidades autónomas de nacimiento de tener una determinada categoría socioeconómica en función de la categoría socioeconómica de origen del padre (porcentaje de fila). Las casillas de la diagonal de cada comunidad autónoma - que se han marcado de color gris- muestran los porcentajes de inmovilidad o herencia de clase, es decir, los hijos no habrían cambiado de categoría social respecto de los padres. Los porcentajes que se muestran por encima de la diagonal expresan movilidad descendente, mientras que los que aparecen por debajo muestran movilidad ascendente. A pesar de que numerosos estudios indiquen que la inmovilidad es mayor en los extremos de la jerarquía de movilidad (Domínguez, 2001; Torche y Wormald, 2007), en nuestro caso son las categorías medias y bajas las que indican mayor porcentaje de herencia. Estos resultados, sin embargo, están indudablemente afectados por la clasificación realizada, que contempla muy pocas categorías en los niveles alto y bajo y muchas más en el medio.

Tras calcular los valores esperados entre las trayectorias de movilidad de origen alto, se observó como no existía en todas las comunidades autónomas el suficiente número de casos para analizar las trayectorias de los inmigrantes con padres situados en esta categoría, así que se descartaron del análisis, lo que no ocurrió con el resto de categorías de origen. De esta manera, entre los de categoría de origen medio son los inmigrantes de Castilla y León, Galicia y País Valenciano los que presentan unos porcentajes más elevados de situación en la 
Tabla 7. Tabla de salida de movilidad intergeneracional por categoría socioeconómica y por comunidad autónoma de nacimiento, varones, 1991

\begin{tabular}{|c|c|c|c|c|c|}
\hline & & Categoría alta & Categoría media & Categoría baja & Total \\
\hline \multirow[t]{3}{*}{ Andalucía } & Categoría alta & $22,50 \%$ & $52,90 \%$ & $24,60 \%$ & $100 \%$ \\
\hline & Categoría media & $14,20 \%$ & $62,40 \%$ & $23,40 \%$ & $100 \%$ \\
\hline & Categoría baja & $7,20 \%$ & $55,90 \%$ & $36,90 \%$ & $100 \%$ \\
\hline \multirow[t]{3}{*}{ Aragón } & Categoría alta & $4,00 \%$ & $70,30 \%$ & $25,60 \%$ & $100 \%$ \\
\hline & Categoría media & $15,20 \%$ & $70,50 \%$ & $14,30 \%$ & $100 \%$ \\
\hline & Categoría baja & $9,20 \%$ & $72,40 \%$ & $18,40 \%$ & $100 \%$ \\
\hline \multirow{3}{*}{$\begin{array}{l}\text { Castilla- } \\
\text { La Mancha }\end{array}$} & Categoría alta & $28,80 \%$ & $61,30 \%$ & $9,90 \%$ & $100 \%$ \\
\hline & Categoría media & $16,20 \%$ & $57,30 \%$ & $26,60 \%$ & $100 \%$ \\
\hline & Categoría baja & $7,70 \%$ & $52,60 \%$ & $39,60 \%$ & $100 \%$ \\
\hline \multirow[t]{3}{*}{ Castilla y León } & Categoría alta & $12,70 \%$ & $64,40 \%$ & $22,90 \%$ & $100 \%$ \\
\hline & Categoría media & $23,80 \%$ & $62,80 \%$ & $13,30 \%$ & $100 \%$ \\
\hline & Categoría baja & $12,20 \%$ & $60,40 \%$ & $27,40 \%$ & $100 \%$ \\
\hline \multirow[t]{3}{*}{ País Valenciano } & Categoría alta & $19,40 \%$ & $76,30 \%$ & $4,30 \%$ & $100 \%$ \\
\hline & Categoría media & $19,60 \%$ & $71,20 \%$ & $9,20 \%$ & $100 \%$ \\
\hline & Categoría baja & $17,10 \%$ & $69,70 \%$ & $13,20 \%$ & $100 \%$ \\
\hline \multirow[t]{3}{*}{ Extremadura } & Categoría alta & $20,10 \%$ & $52,70 \%$ & $27,30 \%$ & $100 \%$ \\
\hline & Categoría media & $17,70 \%$ & $56,40 \%$ & $26,00 \%$ & $100 \%$ \\
\hline & Categoría baja & $9,60 \%$ & $61,80 \%$ & $28,60 \%$ & $100 \%$ \\
\hline \multirow[t]{3}{*}{ Galicia } & Categoría alta & $9,40 \%$ & $63,10 \%$ & $27,40 \%$ & $100 \%$ \\
\hline & Categoría media & $20,00 \%$ & $63,00 \%$ & $17,00 \%$ & $100 \%$ \\
\hline & Categoría baja & $8,50 \%$ & $61,50 \%$ & $30,00 \%$ & $100 \%$ \\
\hline \multirow[t]{3}{*}{ Murcia } & Categoría alta & $0,00 \%$ & $67,90 \%$ & $32,10 \%$ & $100 \%$ \\
\hline & Categoría media & $14,40 \%$ & $62,40 \%$ & $23,20 \%$ & $100 \%$ \\
\hline & Categoría baja & $30,90 \%$ & $46,60 \%$ & $22,50 \%$ & $100 \%$ \\
\hline \multirow[t]{3}{*}{ Resto CCAA } & Categoría alta & $20,90 \%$ & $67,30 \%$ & $11,80 \%$ & $100 \%$ \\
\hline & Categoría media & $19,10 \%$ & $72,60 \%$ & $8,30 \%$ & $100 \%$ \\
\hline & Categoría baja & $15,70 \%$ & $62,10 \%$ & $22,20 \%$ & $100 \%$ \\
\hline \multirow[t]{3}{*}{ Total } & Categoría alta & $18,80 \%$ & $59,30 \%$ & $22,00 \%$ & $100 \%$ \\
\hline & Categoría media & $16,40 \%$ & $63,40 \%$ & $20,20 \%$ & $100 \%$ \\
\hline & Categoría baja & $9,70 \%$ & $58,20 \%$ & $32,20 \%$ & $100 \%$ \\
\hline
\end{tabular}

Fuente: elaboración propia a partir de la ESD91 (INE)

categoría alta y, por tanto, de haber experimentado movilidad ascendente respecto a sus padres: un 25\%, un 20\% y un 19\%, respectivamente. En cambio, son los andaluces y los murcianos, con un 14\%, los de menor movilidad social ascendente. En cuanto a los ascensos correspondientes a los hijos de padres de categoría baja, también los valencianos, aunque seguidos por los murcianos, experimentan proporciones más altas de ascenso social. Pero si tenemos en cuenta a todos los migrantes de categoría baja que han experimentado ascenso social, esto es al conjunto de los que han acabado en la categoría media y alta, el dominio de los valencianos es acaparador, con un $87 \%$ de los casos, segui- 
dos de los aragoneses, con casi un $82 \%$. Por el contrario, este ascenso solo lo experimenta un $60 \%$ de los castellanomanchegos y un $63 \%$ de los andaluces del mismo origen social.

Sobre los valores de herencia de categoría, obtenemos lo siguiente. Primeramente, para la categoría media, son los valencianos — seguidos de los aragoneses a muy poca distancia - los que mayor herencia social en esta categoría experimentan, con un $71 \%$. En la categoría baja, por el contrario, son primero los castellanomanchegos $\mathrm{y}$, a continuación, los andaluces los que más inmovilidad experimentan, con un $39 \%$ y un $37 \%$, respectivamente.

La tabla 8 informa sobre cómo se recluta a los miembros de cada categoría socioeconómica o sobre cuál es la estructura de origen de cada categoría. En este caso, tampoco comentaremos los casos referidos a la categoría alta de origen, al existir muy pocos. El autorreclutamiento en la categoría baja de inmigrantes es generalizado en todas las comunidades autónomas. Los casos más extremos corresponden a castellanomanchegos, castellanoleoneses y andaluces, con un $79 \%$, un $78 \%$ y un $72 \%$ respectivamente de hijos de categoría baja que provienen de la misma categoría socioeconómica. Por el contrario, los que menor autorreclutamiento disponen en la categoría baja son los aragoneses y los murcianos. En cuanto a los hijos situados en la categoría media, todos los efectivos tenían un origen mayoritario de la categoría más baja de clasificación, de manera que, entre un mínimo de un 54\% de los aragoneses, cercano al 57\% de los valencianos, y un máximo de un $68 \%$ de los castellanomanchegos, provenían de la categoría inferior. Los máximos porcentajes de hijos de categoría alta con un padre de categoría baja se presentan entre los inmigrantes nacidos en el País Valenciano (un 54\%) y en Andalucía (un 52\%).

Como decíamos, para captar la movilidad neta de los efectos de cambio estructural, se realizó el cálculo de las razones de momios (odds ratio), las cuales expresan las ventajas competitivas que individuos de distinto origen tienen de alcanzar un determinado destino en la estructura ocupacional sobre una categoría de referencia, en nuestro caso la baja. De este modo, se observa a través de la tabla 9 que, entre los inmigrantes castellanomanchegos, la probabilidad de ser de categoría alta se multiplica por 15 con relación a ser de baja si el origen de sus padres es de categoría alta y se multiplica por 3 si su origen es de categoría media. Por tanto, valores elevados indican mayor desigualdad al acceso a un destino en función de la categoría del padre. No obstante, dado que en la muestra los inmigrantes de origen de categoría alta, a excepción de los andaluces, también son muy escasos, nos centraremos en comentar los parámetros de la categoría de origen media en relación con la de origen baja. Así, los inmigrantes de Castilla y León tienen más del doble de probabilidades de ser de categoría media si provienen de la misma categoría — señalada con un valor del 2,14- que si proceden de la baja. Esta misma relación se sitúa siempre por debajo de 2 en el resto de orígenes, con un máximo de 1,81 entre los inmigrantes gallegos y un mínimo entre los aragoneses, con 1,25. Por tanto, se podría afirmar que, a excepción de los castellanoleoneses, las diferencias de acceso entre la categoría media y la baja para acceder a la categoría media son 
Tabla 8. Tabla de entrada de movilidad intergeneracional por categoría socioeconómica por comunidad autónoma de nacimiento, varones, 1991

\begin{tabular}{|c|c|c|c|c|}
\hline & & Categoría alta & Categoría media & Categoría baja \\
\hline \multirow[t]{4}{*}{ Andalucía } & Categoría alta & $16,90 \%$ & $7,20 \%$ & $6,00 \%$ \\
\hline & Categoría media & $39,70 \%$ & $31,60 \%$ & $21,30 \%$ \\
\hline & Categoría baja & $43,40 \%$ & $61,20 \%$ & $72,70 \%$ \\
\hline & & $100 \%$ & $100 \%$ & $100 \%$ \\
\hline \multirow[t]{4}{*}{ Aragón } & Categoría alta & $2,40 \%$ & $6,70 \%$ & $10,10 \%$ \\
\hline & Categoría media & $53,80 \%$ & $39,20 \%$ & $32,80 \%$ \\
\hline & Categoría baja & $43,80 \%$ & $54,20 \%$ & $57,20 \%$ \\
\hline & & $100 \%$ & $100 \%$ & $100 \%$ \\
\hline \multirow[t]{4}{*}{ Castilla-La Mancha } & Categoría alta & $13,50 \%$ & $5,80 \%$ & $1,50 \%$ \\
\hline & Categoría media & $36,80 \%$ & $26,30 \%$ & $19,00 \%$ \\
\hline & Categoría baja & $49,70 \%$ & $67,90 \%$ & $79,60 \%$ \\
\hline & & $100 \%$ & $100 \%$ & $100 \%$ \\
\hline \multirow[t]{4}{*}{ Castilla y León } & Categoría alta & $4,70 \%$ & $6,00 \%$ & $5,60 \%$ \\
\hline & Categoría media & $43,40 \%$ & $29,10 \%$ & $16,30 \%$ \\
\hline & Categoría baja & $51,90 \%$ & $65,00 \%$ & $78,00 \%$ \\
\hline & & $100 \%$ & $100 \%$ & $100 \%$ \\
\hline \multirow[t]{4}{*}{ País Valenciano } & Categoría alta & $13,40 \%$ & $13,40 \%$ & $5,00 \%$ \\
\hline & Categoría media & $32,20 \%$ & $29,90 \%$ & $25,20 \%$ \\
\hline & Categoría baja & $54,40 \%$ & $56,60 \%$ & $69,80 \%$ \\
\hline & & $100 \%$ & $100 \%$ & $100 \%$ \\
\hline \multirow[t]{4}{*}{ Extremadura } & Categoría alta & $12,40 \%$ & $7,10 \%$ & $7,80 \%$ \\
\hline & Categoría media & $41,10 \%$ & $28,30 \%$ & $28,00 \%$ \\
\hline & Categoría baja & $46,50 \%$ & $64,60 \%$ & $64,10 \%$ \\
\hline & & $100 \%$ & $100 \%$ & $100 \%$ \\
\hline \multirow[t]{4}{*}{ Galicia } & Categoría alta & $13,40 \%$ & $17,00 \%$ & $17,70 \%$ \\
\hline & Categoría media & $46,60 \%$ & $27,80 \%$ & $17,90 \%$ \\
\hline & Categoría baja & $40,00 \%$ & $55,20 \%$ & $64,40 \%$ \\
\hline & & $100 \%$ & $100 \%$ & $100 \%$ \\
\hline \multirow[t]{4}{*}{ Murcia } & Categoría alta & $0,00 \%$ & $11,00 \%$ & $11,70 \%$ \\
\hline & Categoría media & $17,50 \%$ & $33,60 \%$ & $28,20 \%$ \\
\hline & Categoría baja & $82,50 \%$ & $55,30 \%$ & $60,10 \%$ \\
\hline & & $100 \%$ & $100 \%$ & $100 \%$ \\
\hline \multirow{4}{*}{ Resto CCAA } & Categoría alta & $22,90 \%$ & $19,90 \%$ & $18,30 \%$ \\
\hline & Categoría media & $52,20 \%$ & $53,50 \%$ & $31,90 \%$ \\
\hline & Categoría baja & $25,00 \%$ & $26,60 \%$ & $49,80 \%$ \\
\hline & & $100 \%$ & $100 \%$ & $100 \%$ \\
\hline \multirow{4}{*}{ Total } & Categoría alta & $12,80 \%$ & $8,50 \%$ & $6,80 \%$ \\
\hline & Categoría media & $40,10 \%$ & $32,50 \%$ & $22,40 \%$ \\
\hline & Categoría baja & $47,00 \%$ & $59,10 \%$ & $70,90 \%$ \\
\hline & & $100 \%$ & $100 \%$ & $100 \%$ \\
\hline
\end{tabular}

Fuente: elaboración propia a partir de la ESD91 (INE) 
Tabla 9. Razones de momios (odds ratio) de la categoría ocupacional de los padres (origen) e hijos (destino) por comunidad autónoma de nacimiento, varones, 1991

\begin{tabular}{|c|c|c|c|c|}
\hline & & Categoría alta & Categoría media & Categoría baja \\
\hline \multirow[t]{3}{*}{ Andalucía } & Categoría alta & 4,69 & 1,42 & 1 \\
\hline & Categoría media & 3,11 & 1,76 & 1 \\
\hline & Categoría baja & 1 & 1 & 1 \\
\hline \multirow[t]{3}{*}{ Aragón } & Categoría alta & 0,31 & 0,70 & 1 \\
\hline & Categoría media & 2,13 & 1,25 & 1 \\
\hline & Categoría baja & 1 & 1 & 1 \\
\hline \multirow[t]{3}{*}{ Castilla-La Mancha } & Categoría alta & 14,96 & 4,66 & 1 \\
\hline & Categoría media & 3,13 & 1,62 & 1 \\
\hline & Categoría baja & 1 & 1 & 1 \\
\hline \multirow[t]{3}{*}{ Castilla y León } & Categoría alta & 1,25 & 1,28 & 1 \\
\hline & Categoría media & 4,02 & 2,14 & 1 \\
\hline & Categoría baja & 1 & 1 & 1 \\
\hline \multirow[t]{3}{*}{ País Valenciano } & Categoría alta & 3,48 & 3,36 & 1 \\
\hline & Categoría media & 1,64 & 1,47 & 1 \\
\hline & Categoría baja & 1 & 1 & 1 \\
\hline \multirow[t]{3}{*}{ Extremadura } & Categoría alta & 2,19 & 0,89 & 1 \\
\hline & Categoría media & 2,03 & 1,00 & 1 \\
\hline & Categoría baja & 1 & 1 & 1 \\
\hline \multirow[t]{3}{*}{ Galicia } & Categoría alta & 1,21 & 1,12 & 1 \\
\hline & Categoría media & 4,15 & 1,81 & 1 \\
\hline & Categoría baja & 1,00 & 1,00 & 1 \\
\hline \multirow[t]{3}{*}{ Murcia } & Categoría alta & - & 1,02 & 1 \\
\hline & Categoría media & 0,45 & 1,30 & 1 \\
\hline & Categoría baja & 1 & 1 & 1 \\
\hline \multirow[t]{3}{*}{ Resto CCAA } & Categoría alta & 2,50 & 2,04 & 1 \\
\hline & Categoría media & 3,25 & 3,13 & 1 \\
\hline & Categoría baja & 1 & 1 & 1 \\
\hline \multirow[t]{3}{*}{ Total } & Categoría alta & 2,84 & 1,49 & 1 \\
\hline & Categoría media & 2,70 & 1,74 & 1 \\
\hline & Categoría baja & 1 & 1 & 1 \\
\hline
\end{tabular}

Fuente: elaboración propia a partir de la ESD91 (INE)

mínimas e incluso - en el caso de los extremeños — inexistentes. En cambio, en el acceso a la categoría alta de los de origen de categoría media en comparación con la baja sí que se han observado diferencias más significativas. Así, son gallegos (4,15 puntos), castellanoleoneses $(4,02)$, castellanomanchegos $(3,13)$ y andaluces $(3,11)$ los que muestran los valores más altos. Ahora bien, las diferencias de acceso por origen entre la categoría media y la baja para acceder a esta categoría de destino son mucho menores en valencianos (1,64 puntos), extremeños $(2,03)$ y aragoneses $(2,13)$, lo que nos indicaría menores desigualdades de acceso entre estos orígenes y por tanto mayor permeabilidad social. 
Tabla 10. Categoría ocupacional del hijo respecto al padre, varones, $\operatorname{Exp}(\beta)$

\begin{tabular}{|c|c|c|c|c|c|c|}
\hline & \multicolumn{2}{|c|}{$\begin{array}{c}\text { Modelo } 1 \\
\text { Categoría baja (inmov. Ref.) }\end{array}$} & \multicolumn{4}{|c|}{$\begin{array}{c}\text { Modelo } 2 \\
\text { Categoría media (inmov. Ref.) }\end{array}$} \\
\hline & Ascen (1) & Sig. & Ascen (1) & Sig. & Descen (2) & Sig, \\
\hline Andalucía & 0,233 & $* * *$ & 0,946 & NS & 3,064 & NS \\
\hline Aragón & 0,68 & NS & 0,861 & NS & 1,625 & NS \\
\hline Castilla-La Mancha & 0,228 & $\star \star$ & 1,162 & NS & 3,777 & NS \\
\hline Castilla y León & 0,361 & * & 1,605 & NS & 1,745 & NS \\
\hline Extremadura & 0,346 & * & 1,337 & NS & 3,798 & * \\
\hline Galicia & 0,327 & * & 1,333 & NS & 2,205 & NS \\
\hline Murcia & 0,537 & NS & 0,839 & NS & 2,875 & NS \\
\hline Resto CCAA & 0,507 & NS & 1,117 & NS & 0,939 & NS \\
\hline Comunidad Valenciana & Ref. & & Ref. & & Ref. & \\
\hline
\end{tabular}

Fuente: elaboración propia a partir de la ESD91 (INE)

Un último análisis de la movilidad relativa se realizó a través de dos modelos de regresión logística, uno binomial y otro multinomial (tabla 10). En ambos modelos se ha controlado la edad, y la categoría de referencia es la comunidad autónoma de nacimiento, que es la Comunidad Valenciana. El primero se elaboró para los individuos cuya categoría de origen del padre era baja, ya que, por definición, los hijos solo pueden experimentar un movimiento de ascensión de categoría o inmovilidad. La variable dependiente es la propensión a experimentar una ascensión frente a la inmovilidad. El modelo multinomial se realizó para la categoría de origen media, y la variable dependiente es la probabilidad de experimentar ascensión de categoría frente a la inmovilidad, por un lado, y un descenso frente a la inmovilidad, por el otro.

Tal como se puede ver en el modelo 1 de la tabla 10, los inmigrantes de Andalucía, las dos Castillas, Extremadura y Galicia que provienen de un padre de categoría socioeconómica baja presentan propensiones de ascensión social significativamente más bajas que los inmigrantes que tienen el padre del mismo origen del País Valenciano. Asimismo, si consideramos la inversa de los parámetros, los valencianos que provienen por parte de padre de una categoría baja tienen 4 veces más propensión al ascenso que los andaluces y los castellanomanchegos, y 3 veces más que los gallegos, los extremeños $(2,9)$ y los castellanoleoneses $(2,7)$.

Con relación al modelo 2 , no se encuentran diferencias significativas respecto al ascenso, mientras que únicamente se observa algún tipo de diferencia significativa al descenso - frente a la inmovilidad - con los inmigrantes extremeños. $\mathrm{O}$, dicho de otra manera, los extremeños de categoría media presentan casi 4 veces más propensión al descenso que a la inmovilidad que los valencianos. En Andalucía y Castilla-La Mancha el parámetro también triplica al de la Comunidad Valenciana, pero no tienen significación estadística. 


\section{Conclusiones}

Aunque la Encuesta Sociodemográfica sea probablemente la mejor encuesta longitudinal hecha en España para analizar la movilidad social — no solo por su tamaño muestral, sino también por ser biográfica一, resulta con todo limitada para el análisis de la movilidad social de los inmigrantes valencianos en Cataluña y, sobre todo, de sus determinantes. Pese a ello, se han aportado evidencias empíricas suficientes, aunque no definitivas, de una mejora de la situación social de los valencianos residentes en Cataluña en 1991 después de migrar, respecto a sí mismos y a sus progenitores, por una parte, y de una mayor movilidad social de los propios migrantes valencianos respecto a otros orígenes autonómicos, por otra.

La población valenciana que en 1991 vivía en Cataluña era heredera de una corriente migratoria histórica ya iniciada durante el siglo XIX. Y es que, aunque en 1991 apenas quedasen rastros en Cataluña de las migraciones más antiguas, el contacto continuo de estas dos poblaciones producido desde hacía más de 100 años, junto con una afinidad cultural e idiomática, podrían explicar el mayor grado de movilidad social del colectivo valenciano en comparación con la de los inmigrantes de otras comunidades autónomas. Además, aunque muchos de los valencianos provenían de zonas del interior, algunas castellanoparlantes, una gran mayoría manifestó entender el catalán, lo que, junto con el elevado número de matrimonios exogámicos con catalanes, les colocaría todavía con más ventaja frente a otros inmigrantes de cara a un posible ascenso social.

Los cálculos obtenidos denotan indicios de un cierto éxito «social» en la movilidad intrageneracional de los valencianos, por el hecho de ser el colectivo que más cambia su perfil comparado con el conjunto después de migrar y estar sobrerrepresentado en los sectores económicos o en las situaciones profesionales de más prestigio en nuestra clasificación, a parte de los funcionarios. Es cierto que otros orígenes estaban también sobrerrepresentados en estos sectores, pero lo eran antes y después de migrar, es decir, no hubo un cambio de situación como en el caso valenciano. Igualmente, para las mujeres los resultados no dan muestras de una movilidad ascendente intrageneracional, aunque hay que tener cautela con las conclusiones porque contamos todavía con una muestra más reducida de casos que en los hombres por las salidas de la ocupación. No obstante, resulta interesante destacar que, si bien es una característica común de la movilidad ocupacional del conjunto de inmigrantes que diez años después de migrar aumente la ocupación masculina y disminuya la femenina respecto al año previo de la inmigración, esto último es más patente en el colectivo de valencianas. Este hecho podría interpretarse como un indicio más del éxito de la inmigración valenciana si presuponemos que entonces el modelo legítimo de pareja imperante fuese el breadwiner, el del hombre mantenedor del hogar.

Respecto a la movilidad intergeneracional, la migración valenciana ha mostrado las máximas tasas brutas de movilidad ascendente, pero también 
los máximos niveles de movilidad relativa. Teniendo en cuenta que la antigüedad de los flujos es mayor que en otros colectivos de migrantes y dado que el análisis solo controlaba parcialmente este hecho, es lógico pensar que los cambios en la estructura ocupacional y educativa debidos al tiempo afectasen particularmente más a los valencianos y quedasen reflejados en una mayor movilidad social. Los valencianos son el grupo migrante con una tasa de movilidad bruta ascendente más elevada, seguida por la de los castellanoleoneses. Además, registran la mayor diferencia entre la tasa de movilidad bruta ascendente y la de inmovilidad y también gozan del mayor índice Duncan, lo que significa que el valenciano es el grupo que registra mayores movimientos de movilidad real de padres a hijos — sea por cambios estructurales o por movilidad neta-. Movimientos que en algunos casos les sitúan en primera posición en los cálculos de las tablas e índices de movilidad social o, en el peor de los casos, acompañados de otros orígenes como Castilla y León y Aragón. Posiciones que, respecto a los primeros, podrían deberse al mayor capital educativo constatado desde muchas generaciones anteriores (Reher et al., 1993) o, respecto a los segundos, derivarse de la raigambre de los movimientos migratorios - y las cadenas que los habrían mantenido- establecidos desde finales del siglo XIX en Cataluña (Aracil et al., 1996; García, 1974).

El análisis de las tablas de salida y de entrada refuerza nuestras hipótesis, al concluir entre los valencianos de origen de categoría baja la mayor movilidad social de padres a hijos, aunque entre los de categoría media, sin embargo, son los hijos castellanoleoneses los que mayor porcentaje de movilidad ascendente experimentan respecto a sus padres. Asimismo, a través de las odds ratio, se ha constatado una mayor desigualdad en el acceso a la categoría alta de los hijos respecto a sus padres entre gallegos, castellanoleoneses, castellanomanchegos y andaluces que entre valencianos, extremeños y aragoneses, lo cual denota una mayor permeabilidad entre las categoría sociales de estos últimos orígenes y, por consiguiente, una mayor ventana de oportunidades para pasar de la categoría baja o media a la alta. Los modelos de regresión, que controlan el efecto de las diferencias de edad de los inmigrantes, refuerzan estos resultados, aunque con matices: los valencianos se distinguen de una mayor movilidad social que el resto de inmigrantes, sobre todo cuando provienen de una categoría socioeconómica baja del padre y no tanto si la procedencia es de la categoría media. Los datos, sin embargo, no permiten abordar en los modelos determinantes tan importantes como el efecto del período en el momento de llegada, al que Silvestre et al. (2015) achacan una importancia crucial para explicar una mejor situación social, ni tampoco el tiempo de residencia en Cataluña, el tipo de inmigración individual o familiar o las diferencias de nivel de instrucción, sin duda factores decisivos de la movilidad.

Una última reflexión consistiría en preguntarse si podemos extrapolar alguna interpretación de futuro en relación con la inmigración internacional reciente. De entrada, si bien es cierto que tanto las migraciones internas en España como las internacionales recogen una diversidad de estrategias 
migratorias que trascienden la división entre migración interna y migración internacional (Domingo et al., 2011), posiblemente hay una serie de factores clave determinantes en los procesos de movilidad social que exigen cautela a la hora de realizar las comparaciones: 1) el contexto restrictivo a la inmigración internacional en comparación con la interna; 2) el mayor peso de la migración familiar en las migraciones internas, condicionado por el punto anterior; 3) el mayor grado de feminización de las corrientes inmigratorias internacionales; 4) los cambios en los modelos familiares y la menor estabilidad de los lazos, y 5) el contexto trasnacional de los procesos de movilidad social que deriva en una construcción social no estática del espacio social. Todos estos factores complejizan los procesos actuales de movilidad social y en muchos casos pueden dificultarlos. Es esperable, no obstante, que la cercanía cultural de algunos colectivos por la vinculación histórica de algunos orígenes con Cataluña y, en especial, el conocimiento de una de sus lenguas suponga de entrada una ventaja en los procesos de movilidad social, como puede haber ocurrido en el caso de los valencianos. El impacto de la tradición migratoria y la demanda específica de población inmigrada serán también elementos que resultarán claves. Finalmente, cabe decir que la pobreza de fuentes estadísticas cuantitativas para el estudio de la movilidad social de la migración interna española no debería permitirse en un país que ha recibido en tan poco tiempo un flujo tan importante de inmigrantes, ya que, aunque Cataluña siempre haya sido una sociedad receptora de inmigrantes, los desafíos a la movilidad social, y por ende a la cohesión social, pueden ser mayores y exigen conocimientos adecuados para afrontarlos.

En relación con la inmigración valenciana y sus fuentes de estudio, futuros análisis cualitativos, a través de entrevistas en profundidad a migrantes valencianos de la segunda y la tercera oleadas del siglo XX, pero también a catalanes descendientes de migrantes valencianos de la primera oleada, deberían servirnos para profundizar en los determinantes de la movilidad social en este colectivo tan singular.

\section{Referencias bibliográficas}

Aracil, Rafael; Ferrer, Llorenç; Recaño, Joaquín y SEgura, Antoni (1996). «La inmigración en la Cataluña rural (1860-1940): Estructura demográfica y componentes espaciales». En: ZÁRraGA, Karmele (coord.) y GonZÁlEZ, Manuel (coord.). Los movimientos migratorios en la construcción de las sociedades modernas. Bilbao: Universidad del País Vasco.

ARANDA, José (1976). «La movilidad social de la población española». Estadistica Española, 70-71, 71-88.

- (1992). «La encuesta sociodemográfica: Objetivos y primeros resultados». En: Segundas Jornadas sobre Demografía Urbana y Regional (Valencia, 29 y 30 de junio de 1992). Madrid: Instituto de Demografía.

ARANGO, Joaquín (1976). «Cambio económico y movimientos migratorios en la España oriental del primer tercio del siglo XX: Algunas hipótesis sobre determinantes y consecuencias». Hacienda Pública Española, 38, 51-80. 
ARBAIZA, Mercedes (1998). «Labor migration during the first phase of Basque industrialization: The labor market and family motivations». The History of the Family, 3 (2), 199-219. <https://doi.org/10.1016/S1081-602X(99)80242-5>

AYSA-LASTRA, María y CACHÓN, Lorenzo (2013). «Movilidad ocupacional segmentada: El caso de los inmigrantes no comunitarios en España». Reis: Revista Española de Investigaciones Sociológicas, 144, 23-47. <https://doi.org/10.5477/cis/reis.144.23>

BABIANO, José (2001). «El vínculo del trabajo: Los emigrantes españoles en la Francia de los treinta gloriosos». Migraciones y Exilios: Cuadernos de la Asociación para el Estudio de los Exilios y Migraciones Ibéricos Contemporáneos, 2, 9-37. Recuperado de <http://www.aemic.org/assets/articulos/40/original/Jos\%C3\%A9_Babiano_ AEMIC_2.pdf?1273220742>.

BERNARDI, Fabrizio (2007). «Movilidad social y dinámicas familiares: Una aplicación al estudio de la emancipación familiar en España». Revista Internacional de Sociologia, 65 (48), 33-54. <https://doi.org/10.3989/ris.2007.i48.67>

BonmaTí, José Fermín (1989). La emigración alicantina a Argelia: Siglo XIX y primer tercio del siglo XX. Alicante: Universidad de Alicante.

Brown, Lawrence A. y CHung, Su-Yeul (2006). «Spatial Segregation, Segregation Indices and the Geographical Perspective». Population, Space and Place, 12, 125 143.

<https://doi.org/10.1002/psp.403>

Cabré, Anna María (1991-1992). "Les migracions en la reproducció de la població catalana, 1880-1980». Documents d'Anàlisi Geogràfica, 19-20, 33-55. Recuperado de <http://www.raco.cat/index.php/DocumentsAnalisi/article/ view/41530/52357>.

- (1999). El sistema català de reproducció. Barcelona. Proa.

CACHÓN, Lorenzo (1989). ¿ ¿Movilidad social o trayectorias de clase? Madrid: CIS.

(2002). "La formación de la "España inmigrante”: Mercado y ciudadanía». Reis, 97, 95-126. Recuperado de <http://www.jstor.org/stable/40184366>.

CAMPMANY, Josep (2015). «L'impacte associatiu i cultural de la immigració valenciana a Gavà». Els moviments migratoris a les terres d'Eramprunyà, Antic escorxador. Begues, 14 de novembre de 2015, Actes. Recuperado de <http://centredestudis.gava. ppe.entitats.diba.cat/wp-content/uploads/sites/10/2016/01/Ponencia-Gava-VIIITrobades-2015.pdf>.

CANDEL, Francisco (1964). Els altres catalans. Barcelona: Edicions 62.

CAPArrós, Antonio y NAVArro, María Lucía (2010). «Movilidad ocupacional de los inmigrantes en España». Investigaciones de Economía de la Educación, 5, 873-890. Recuperado de <http://repec.economicsofeducation.com/2010zaragoza/05-44. $\mathrm{pdf}>$.

CAPEL, Horacio (1967). «Los estudios acerca de las migraciones interiores en España». Revista de Geografía, 1 (1), 77-101.

Carabaña, Julio (1983). «Homogamia y movilidad social». Reis: Revista Española de Investigaciones Sociológicas, 21, 61-82. $<$ https://doi.org/10.2307/40182999>

- (1990). «La movilidad social en Madrid: Una comparación con Cataluña, el País Vasco y Castilla-La Mancha». Economía y Sociedad: Revista de Estudios Regionales de la Comunidad de Madrid, 4, 37-54. 
- (1993). «Desigualdad económica y movilidad social». En: I Simposio sobre Igualdad y Distribución de la Renta y la Riqueza, 5. Madrid: Fundación Argentaria.

- (1996). «Estado de bienestar y movilidad social: Acerca de los trabajadores de los servicios en España». En: VVAA. Dilemas del estado de bienestar. Madrid: Fundación Argentaria.

- (1999). Dos estudios sobre movilidad intergeneracional. Madrid: Fundación Argentaria.

CASADEMONT, Xavier (2016). L'assentament de la immigració andalusa a Olot durant el franquisme: Trajectòries i mobilitat social de la immigració andalusa i els seus descendents. Departament de Pedagogia. Universitat de Girona. Tesis doctoral. Recuperado de <http://dugi-doc.udg.edu:8080/bitstream/handle/10256/12295/ txcf1de1.pdf?sequence $=1>$.

Cobo, Francisco y OrTegA, Teresa María (2004). «Franquismo y cuestión agraria en Andalucía oriental, 1939-1968: Estancamiento económico, fracaso industrializador y emigración». Historia del presente, 3, 105-126. Recuperado de <http:// historiadelpresente.es/sites/default/files/revista/articulos/3/307franquismoycuest ionagrariaenandaluciaoriental1939-1968.estancamientoeconomicofracasoindustrializadoryemigracion.pdf>.

DíEZ, Juan; MARTínEZ, Ubaldo y Porro, María José (1975). «Education and Social Mobility in Spain». Education, Inequality and Life Chances, 1, 563-612.

DíEZ, Juan y PINO, Juan del (1972). «Estratificación y movilidad social en España en la década de los años setenta». En: CAMPO, Salustiano del (dir.). La España de los años 70. I: La Sociedad. Madrid: Moneda y Crédito.

Domingo, Andreu (2012). «Immigració i política demogràfica a l'obra de Josep Antoni Vandellós». Treballs de la Societat Catalana de Geografia, 73, 9-26. $<$ https://doi.org/10.2436/20.3002.01.1>

- (2014). Catalunya al mirall de la immigració. Barcelona: L'Avenç.

Domingo, Andreu y PiTARCH, Kenneth (2015). «La població valenciana a Catalunya al segle XXI: Anàlisi demogràfica i espacial». Treballs de la Societat Catalana de Geografia, 79, 9-37. <https://doi.org/10.2436/20.3002.01.77>

Domingo, Andreu; SABATER, Albert; Bedoya, María Helena y Franch, Xavier (2012). «Regularizaciones y trayectorias de inmigrantes no comunitarios en la provincia de Barcelona». Reis: Revista Española de Investigaciones Sociológicas, 140, 121-146. $<$ https://doi.org/10.5477/cis/reis.140.121>

Domingo, Andreu; Treviño, Rocío y Bueno, Xiana (2011). «Género y estrategias migratorias familiares en la migración interna e internacional en Cataluña». Revista de Demografía Histórica, 29 (2), 59-86. Recuperado de <https://ddd.uab.cat/pub/ artpub/2011/166687/revdemhis_a2011v29n2p59iSPA.pdf >.

Domingo-Salvany, A.; Bacigalupe, A.; Carrasco, J.M.; Espelt, A.; Ferrando, J. y Borrell, C. (2013). «Propuestas de clase social neoweberiana y neomarxista a partir de la Clasificación Nacional de Ocupaciones 2011». Gaceta Sanitaria, 27 (3), 263-272.

Domínguez, Mario (2001). «Movilidad social». En: RodríGueZ, Manuel José (coord.). Temas de Sociología (Volumen 1). Madrid: Huerga y Fierro Editores.

DunCAN, O.D. y DunCAN, B. (1955). "A methodological analysis of segregation indexes». American Sociological Review, 20, 210-217.

ECHEVARRÍA, Javier (1998). «Movilidad social y comportamiento electoral». Reis: Revista Española de Investigaciones Sociológicas, 83, 237-267. <https://doi.org/10.2307/40184127> 
- (1999). La movilidad social en España. San Sebastián de los Reyes. Madrid: Istmo.

FACHELli, Sandra y LÓPEZ-RoldÁN, Pedro (2015). «Somos más móviles incluyendo a la mitad invisible?: Análisis de la movilidad social intergeneracional en España en 2011». Reis: Revista Española de Investigaciones Sociológicas, 150, 41-69. <https://doi.org/10.5477/cis/reis.150.41>

FUNDACIÓN FOESSA (1970). Informe sociológico sobre la situación social en España, 1970. Madrid: Euramérica.

- (1975). Estudios sociológicos sobre la situación social de España, 1975. Madrid: Euramérica.

GALEANO, Juan y BAYONA, Jordi (2015). «Assentament territorial de la població estrangera a l'Àrea Metropolitana de Barcelona en el segle XXI». Recerca $i$ immigració VII: Migracions dels segles XX $i$ XXI, una mirada candeliana, 95-192. Recuperado de <https://ddd.uab.cat/pub/caplli/2015/168403/recerca_immigracioVII_a2015p95.pdf>

GARCíA BARBANCHO, Alfonso (1967). Las migraciones interiores españolas: Estudio cuantitativo desde 1900. Madrid: Estudios del Instituto de Desarrollo Económico.

GARCÍA, Teresa (1974). «Barrios barceloneses de la dictadura de Primo de Rivera». Revista de Geografía, 8 (1), 77-97. Recuperado de <https://dialnet.unirioja.es/servlet/articulo?codigo $=2856495>$.

García, Arlinda y PujadAs, Isabel (1995). «Migraciones interiores en España: Tendencias recientes y perspectivas de futuro (1971-2001)». Revista de Geografía, 29 (3), 9-96. Recuperado de <https://dialnet.unirioja.es/ejemplar/3340>.

GARCÍA, Arlinda y STILlWELl, John (1999). «Inter-provincial migration in Spain: Temporal trends and age-specific patterns». International Journal of Population Geography, 5 (2), 97-115.

<https://doi.org/10.1002/(SICI)1099-1220(199903/04)5:2\%3C97::AID-IJPG126\%3E3.0.CO;2-V>

GOBERNADO, Rafael (1994). «Modernidad y estratificación social: Análisis comparativo de las estructuras sociales de Cataluña y Andalucía». Reis: Revista Española de Investigaciones Sociológicas, 67, 87-108. $<$ https://doi.org/10.2307/40183736>

GONZÁleZ, Juan Jesús (1992). «La construcción empírica de las clases». Política y Sociedad, 11, 99-122. Recuperado de <http://revistas.ucm.es/index.php/POSO/ article/viewFile/POSO9292220099A/30463>.

GONZÁLEZ, Arnau (2007). Valencianistes a Catalunya: Actuació Valencianista d'Esquerra de Barcelona (1932-1937). Catarroja: Afers.

GONZÁLEZ, Francesc (2008). «El papel de los destinos turísticos en la transformación sociodemográfica del litoral mediterráneo español». Boletín de la Asociación de Geógrafos Españoles, 47, 79-107. Recuperado de <http://www.age-geografia.es/ojs/ index.php/bage/article/viewFile/2030/1943>.

Hermosilla, Jorge (1995). «Movimientos migratorios actuales en el País Valenciano». Cuadernos de Geografía, 57, 109-128. Recuperado de <http://roderic.uv.es/ handle/10550/30911>.

HernándeZ, Agustí (2004). "La memòria de l'abandonament». Mètode, 42, 40-51. Recuperado de <http://revistes.iec.cat/index.php/Metode/article/viewFile/45021/45183>.

HERNÁNDEZ, Julio (2002). La emancipación juvenil: Un análisis estadístico aplicado a la Comunidad de Madrid. Departamento de Estadística e Investigación Operativa II. Universidad Complutense de Madrid. Tesis doctoral. Recuperado de <http:// eprints.ucm.es/4680/>. 
MArqués, Ildefonso y Herrera-Usagre, Manuel (2010). «¿Somos más móviles?: Nuevas evidencias sobre la movilidad intergeneracional de clase en España en la segunda mitad del siglo XX». Reis: Revista Española de Investigaciones Sociológicas, 131, 43-73. Recuperado de <http://www.reis.cis.es/REIS/PDF/ REIS_131_021277971526487.pdf>.

MARTÍNEZ, Xavier y MARín, Antoni (2010). Educació i mobilitat social a Catalunya. Barcelona: Fundació Jaume Bofill.

- (2011) Educació i mobilitat social a Catalunya: Actualització amb dades PaD 2009. Barcelona: Fundació Jaume Bofill.

Miret, Pau (2001). Primonupcialidad en España durante el siglo XX: Análisis transversal y comportamientos longitudinales. Departamento de Sociología II. UNED. Tesis doctoral.

- (2005). «Pautas territoriales en la emancipación juvenil en España, cohortes de nacimiento 1924-1968». Papeles de Geografía, 41-42, 161-176. Recuperado de <http://revistas.um.es/geografia/article/view/44381/42491>.

Mirri, Teresa (1996). «Migrantes en las jóvenes sociedades industriales: Integración y diferenciación social». Historia Social, 26, 79-96. Recuperado de <http://www. jstor.org/stable/40340571>.

MÓDENES, Juan Antonio (1998). Flujos espaciales e itinerarios biográficos: La movilidad residencial en el área de Barcelona. Departamento de Geografía. Universitat Autònoma de Barcelona. Tesis doctoral. Recuperado de <http://ddd.uab.cat/ record/127209>.

Morell, Teresa (2012). Valencians a Nova York: El cas de la Marina Alta, 1912-1920. La Pobla Llarga (Valencia): Edicions 96; Pedreguer (Alicante): Institut d'Estudis Comarcals de la Marina Alta.

Murillo, Francisco; Beltrán, Miguel; Castillo, José; Pérez, Alfonso; Díaz, José María y MARTín, Enrique (1983). Informe sociológico sobre el cambio social en España 1975-1983. Madrid: Euramérica.

Olives, José (1969). «Deterioración urbana e inmigración en un barrio del casco antiguo de Barcelona: Sant Cugat del Rec». Revista de Geografía, 3 (1-2), 40-72. Recuperado de <http://hdl.handle.net/10459.1/43419>.

OYÓN, José Luis; MALDONADO, Josep y Griful, Eulàlia (2001). Barcelona 1930: Un atlas social. Barcelona: Edicions UPC.

PASCUAl DE SANS, Àngels (2011). «L'estudi de les migracions a Catalunya, l'estudi de la societat catalana». Revista Catalana de Sociologia, 27, 5-14. Recuperado de <http:// www.raco.cat/index.php/revistasociologia/article/viewFile/251305/336207>.

Pascual de SAns, Àngels y Cardelús, Jordi (1990). Migració i història personal: Investigació sobre la mobilitat des de la perspectiva del retorn. Bellaterra: Universitat Autònoma de Barcelona.

Pascual de Sans, Àngels; Miguel, Verónica de; Morén, Ricard y Solana, Miguel (2002). Migracions a Catalunya: L'estat de la qüestió (1975-2000). Bellaterra: Universitat Autònoma de Barcelona. Servei de Publicacions. Recuperado de $<$ https:// ddd.uab.cat/record/32/>.

PÉREZ, Julio (2001). Transformaciones sociodemográficas en los recorridos generacionales hacia la madurez: Las generaciones españolas 1906-1945. Madrid: Departamento de Sociología II. UNED. Tesis doctoral. Recuperado de <http://hdl.handle. net/10261/16849>.

PÉREZ, Víctor (1971). Emigración y cambio social. Madrid: Ariel.

Pinilla de las Heras, Esteban (1973). Immigració i mobilitat social a Catalunya. Barcelona: Institut Catòlic d'Estudis Socials de Barcelona, fascículos 1-4. 
- (1979). Estudios sobre cambio social y estructuras sociales en Cataluña, 16. Madrid: CIS.

PinOTTI, José Luis y CRUZ, José Ignacio (1992). «Valencianos en Iberoamérica: Identidad e integración». En: VIVES, Pedro; VegA, Pepa y Oyamburu, Jesús (coord.). Historia general de la emigración española a Iberoamérica. Madrid: Ministerio de Trabajo e Inmigración, 443-468.

PiQUERAS, Juan y SANCHís, María del Carmen (1986). «La población y el poblamiento en la comarca de Requena-Utiel». Cuadernos de Geografía, 39-40, 331-344. Recuperado de <http://roderic.uv.es/handle/10550/30777>.

PitARCH, Kenneth y Blanes, Amand (2016). «Emigración internacional valenciana: Una aproximación sociodemográfica». Cuadernos de Geografía, 98, 67-88.

PUJADAS, Isabel (1982). La població de Catalunya: Anàlisi espacial de les interrelacions entre els moviments migratoris i les estructures demogràfiques. Barcelona: Facultat de Geografia i Història. Universitat de Barcelona. Tesis doctoral.

RECAÑO, Joaquín (1996). «Las migraciones interiores en el área mediterránea (18601960)». Papers de Demografia, 120. Centre d'Estudis Demogràfics.

RECAÑO, Joaquín y RoIG, Marta (2003). «Internal migration and inequalities: The influence of migrant origin on educational attainment in Spain». European Sociological Review, 19 (3), 299-317. $<$ https://doi.org/10.1093/esr/19.3.299>

ReHer, David Sven; Pombo, María Nieves y Nogueras, Beatriz (1993). España a la luz del Censo de 1887. Madrid: Instituto Nacional de Estadística.

REQUENA, Félix (2010). «Desarrollo y movilidad social: Análisis comparado entre Andalucía y Cataluña». Papers: Revista de Sociologia, 95 (4), 935-952. $<$ https://doi.org/10.5565/rev/papers/v95n4.78>

Rico, Margarita y GómeZ, Jesús María (2003). «Mujeres y despoblación en el medio rural de Castilla y León». Ager: Revista de Estudios sobre Despoblación y Desarrollo Rural, 3, 151-184. Recuperado de <http://www.redalyc.org/ $\mathrm{html} / 296 / 29600305 />$.

RoDríGUEZ, Jorge (1993). "Movilidad social y cambio social en España». Reis: Revista Española de Investigaciones Sociológicas, 61, 77-125. $<$ https://doi.org/10.2307/40183618>

RoIz, Miguel (1983). «Estratificación, pobreza y cambio en España en la década de los años 80». Documentación Social: Revista de Estudios Sociales y de Sociología Aplicada, 50, 49-68.

Romero, Joan y Domingo, Concepción (1979). «La dicotomía interior-litoral en la Provincia de Castellón y sus consecuencias demográficas». Cuadernos de Geografía, 25, 181-192. Recuperado de <http://roderic.uv.es/handle/10550/26840>.

SABATER, Albert; GALEANO, Juan y DOMINGO, Andreu (2013). «La transformación de las comunidades mayoritarias y la formación y evolución de los enclaves étnicos residenciales en España». Migraciones, 34, 11-44. Recuperado de <http://revistas. upcomillas.es/index.php/revistamigraciones/article/view/2245/1971>.

SALIDO, Olga (1996). La movilidad ocupacional femenina en España: Una comparación por sexo. Madrid: Departamento de Sociología IV. Facultad de Ciencias Políticas y Sociología. Universidad Complutense de Madrid. Tesis doctoral. Recuperado de <http://eprints.ucm.es/4039/>.

- (2002). «La participación laboral de las mujeres en España: Cifras para un debate». Documento de Trabajo, 2 (15). Recuperado de <http://cdd.emakumeak.org/ ficheros/0000/0191/asp058.pdf>. 
SÁNCHEZ, Jesús Javier (1998). «Comportamiento reproductivo de los matrimonios en Navarra y el País Vasco: Análisis de la Encuesta Sociodemográfica del INE de 1991». Reis: Revista Española de Investigaciones Sociológicas, 83, 217-235. <https://doi.org/10.2307/40184126>

SEBASTIÀ, Rafael (1997). «La industria del calzado en la provincia de Alicante: Características de su evolución reciente (1970-1991)». Investigaciones Geográficas, 18, 81-98. <https://doi.org/10.14198/INGEO1997.18.10>

SilveSTRE, Javier (2002). "Las emigraciones interiores en España durante los siglos XIX y XX: Una revisión bibliográfica». Ager. Revista de Estudios sobre Despoblación y Desarrollo Rural, 2, 227-248. Recuperado de <http://www.ceddar.org/content/ files/articulof_256_08_Ager\%202,8.pdf>.

- (2007). «Temporary Internal Migrations in Spain, 1860-1930». Social Science History, 31 (4), 539-574. $<$ https://doi.org/10.1017/S0145553200013857>

- (2010). «Las migraciones interiores en España, 1860-2007 (1)». Historia y Política, 23, 113-134. Recuperado de <https://recyt.fecyt.es/index.php/Hyp/article/ view/44425/26013>.

Silvestre, Javier; AyUdA, Maria Isabel y Pinilla, Vicente (2015). "The occupational attainment of migrants and natives in Barcelona, 1930». Economic History Review, 68 (3), 985-1015. $<$ https://doi.org/10.1111/ehr.12090>

SimÓn, Hipólito; Ramos, Raúl y SANROMÁ, Esteban (2010). «Movilidad ocupacional de los inmigrantes en una economía de bajas cualificaciones: El caso de España». Document de Treball. Xarxa de Referència en Economia Aplicada 6. Barcelona: Departament d'Innovació, Universitats i Empresa. Generalitat de Catalunya. Recuperado de <http://hdl.handle.net/10045/27914>.

SolÉ, Carlota (1981). «Andaluces en Cataluña». Papers: Revista de Sociologia, 16, 149-181. $<$ https://doi.org/10.5565/rev/papers/v16n0.1245>

- (1988) Catalunya, societat receptora d'immigrants: Anàlisi comparativa de dues enquestes, 1978 i 1983. Vol. 1 i 2 . Barcelona. Institut d'Estudis Catalans.

SoroKIn, Pitirim Aleksandrovich (1927). Social mobility. Nueva York: Harper \& Brothers.

STANEK, Mikolaj y VeIra, Alberto (2009). «Occupational Transitions and Social Mobility at Migration to Spain». Documentos de Trabajo GEPS, 4 (3). Universidad Complutense de Madrid. $<$ https://doi.org/10.3282/DT004(III)2009>

Susino, Joaquín (2003). Movilidad residencial: Procesos demográficos, estrategias familiares y estructura social. Granada: Departamento de Sociología. Universidad de Granada. Tesis doctoral. Recuperado de <http://hdl.handle.net/10481/36716>.

TORChE, Florencia y WORMALD, Guillermo (2007). "Chile, entre la adscripción y el logro». En: FRANCO, Rolando; LEÓN, Arturo y ATRIA, Raúl (coord.). Estratificación y movilidad social en América Latina. Santiago de Chile: LOM Ediciones.

VANDELlós, Josep Antoni (1935). Catalunya, poble decadent. Barcelona. Edicions 62, 1985. VIDAL, Tomàs y RECAÑo, Joaquín (1996). "La mobilitat interior als Països Catalans». En: Carreras, Carles (dir.). Geografia General dels Països Catalans. Vol. III: La Població. Barcelona: Enciclopèdia Catalana, 50-66.

VILÁ, Joan (1959). «La aportación murciana al crecimiento poblacional de Barcelona». Anales de la Universidad de Murcia: Filosofia y Letras, 17 (3-4), 76-93. Recuperado de <http://hdl.handle.net/10201/21734>. 